Article

\title{
Impact of High-Pressure Processed Onion on Colonic Metabolism Using a Dynamic Gastrointestinal Digestion Simulator
}

\author{
Irene Fernández-Jalao ${ }^{1}$, Claudia Balderas ${ }^{1}$, María V. Calvo ${ }^{2} \mathbb{D}$, Javier Fontecha ${ }^{2}{ }^{\mathbb{D}}$, \\ Concepción Sánchez-Moreno ${ }^{1}\left(\mathbb{D}\right.$ and Begoña De Ancos ${ }^{1, *}$ (D) \\ 1 Department of Characterization, Quality and Safety, Institute of Food Science, \\ Technology and Nutrition (ICTAN-CSIC), 28040 Madrid, Spain; irene.fernandez@ictan.csic.es (I.F.-J.); \\ claudia.balderas03@gmail.com (C.B.); csanchezm@ictan.csic.es (C.S.-M.) \\ 2 Department of Bioactivity and Food Analysis, Institute of Food Science Research (CIAL, CSIC-UAM), \\ 28049 Madrid, Spain; mv.calvo@csic.es (M.V.C.); j.fontecha@csic.es (J.F.) \\ * Correspondence: ancos@ictan.csic.es; Tel.: +34-915-492-300
}

check for updates

Citation: Fernández-Jalao, I.; Balderas, C.; Calvo, M.V.; Fontecha, J.; Sánchez-Moreno, C.; De Ancos, B. Impact of High-Pressure Processed Onion on Colonic Metabolism Using a Dynamic Gastrointestinal Digestion Simulator. Metabolites 2021, 11, 262. https://doi.org/10.3390/

metabo11050262

Academic Editor: Jose M. Lorenzo

Received: 17 March 2021

Accepted: 20 April 2021

Published: 22 April 2021

Publisher's Note: MDPI stays neutral with regard to jurisdictional claims in published maps and institutional affiliations.

Copyright: (c) 2021 by the authors. Licensee MDPI, Basel, Switzerland. This article is an open access article distributed under the terms and conditions of the Creative Commons Attribution (CC BY) license (https:/ / creativecommons.org/licenses/by/ $4.0 /)$.

\begin{abstract}
Onions are the main dietary source of flavonols that have been associated with important health-promoting properties. Onion treated by high-pressure processing (HPP-treated onion) was subjected to a dynamic gastrointestinal digestion and colon fermentation simulator (DGID-CF) to study the effect on the gut microbiota metabolism in the three colon regions (ascending-AC, transverse-TC, and descending-DC) by means of chronic feeding with $27 \mathrm{~g} /$ day for 14 days. HPPtreated onion presented a high content of the flavonols quercetin-3,4'-diglucoside and quercetin- $4^{\prime}$ glucoside, and a large percentage of them reached the AC without change. TC and DC progressively increased the total phenolic metabolites 2.5 times respective to day 2, mainly 3-hydroxyphenylacetic, 4-hydroxyphenylacetic, 3-(4-hydroxyphenyl)-propionic, and 3,4-dihydroxyphenylpropionic acids. In addition, the chronic feeding increased the beneficial colon bacteria Bifidobacterium spp. and Lactobacillus spp. and the production of total SCFAs (acetic, propionic, and butyric acids) 9 times (AC), 2.2 times (TC), and 4.4 times (DC) respective to day 1. A multivariate analysis (principal component analysis, PCA) showed a clear separation between the three colon regions based on their phenolic composition (precursors and metabolites). These results showed that HPP-treated onion modulated the human gut microbiota's metabolism and the DGID-CF is a good system to study these changes.
\end{abstract}

Keywords: gastrointestinal digestion-colon fermentation model; high-pressure processing; onion; quercetin glycosides metabolites; gut microbiota; short-chain fatty acids

\section{Introduction}

Onions (Allium cepa L.) are the second main crop grown worldwide after tomatoes with a current production estimated at 96.77 million tons [1] and are considered a primary ingredient of major worldwide diets [2]. Onions are also an essential source of nutrients and bioactive compounds (such as phenolic and organosulfur compounds) and dietary fibers (mainly oligosaccharides) [3]. Daily onion consumption has long been associated with health-promoting properties including antimicrobial, antibiotic, antioxidant, analgesic, antiplatelet, antithrombotic, anti-inflammatory, antidiabetic, anticarcinogenic, hypolipidemic, antihypertensive, hepatoprotective, and immunoprotective effects [2,3]. The health-protecting effects of onion consumption have been extensively related with their phenolic composition, mainly flavonols, a subgroup of flavonoids [4,5]. Onion is one of the main dietary sources of the flavonol quercetin (Q) along with apples. In onions, quercetin is linked to glucose in the form of monoglucosides such as Q-4'-O-glucoside, diglucosides such as Q-3, $4^{\prime}$-di-O-glucoside, and triglucosides such as Q-3,7' $4^{\prime}$-tri-O-glucoside [6]. The 
beneficial properties of quercetin are closely related to its chemical structure, which gives it excellent antioxidant power to act against reactive oxygen species and free radicals and inhibit pro-oxidant enzymes (lipoxygenase, xanthine oxidase, NADPH oxidase) [7]. Moreover, quercetin has shown cardioprotective effects related to its anti-inflammatory activity, inhibition of LDL oxidation, reduction of adhesion molecules, platelet antiaggregating, and vasodilator effects $[8,9]$.

However, to exert the biological functions of flavonoids, they must be first released from the food matrix during gastrointestinal digestion and become available (bioaccessible) for further intestinal absorption, and later, reach the target organ or systemic circulation (bioavailable). Bioaccessibility and the absorption of flavonoids are determined by different factors such as chemical structure, degree of polymerization or glycosylation, solubility and conjugation with other phenolics, the food matrix composition, possible interactions with other food components present in the diet (carbohydrates, lipids, proteins, fiber, etc.) [10], and food processing technologies such as high-pressure processing (HPP) [11]. HPP has been proposed as an alternative to thermal processing technologies to produce high-quality, safe, and fresh-like plant-derived foods. HPP promotes microbiological and enzymatic inactivation in vegetables and fruits, and thus this technology preserves the compounds responsible for their sensory and nutritional quality and health-promoting characteristics [11]. Moreover, certain HPP treatments induce the breakage of cellular structures allowing the release of phenolic compounds into the extracellular medium, thus increasing their bioaccessibility [11].

The recovery rates of flavonoids in plasma and urine in most absorption studies are usually much less than $50 \%$ of the initial content in the food, showing their low bioaccessibility [12]. Accordingly, the majority of flavonoids reach the colon intact, where they undergo an extensive metabolism by the gut microbiota $[13,14]$. The microbial metabolism of flavonoids in the colon depends on the specific abilities of the bacteria strains to cleave certain chemical bonds [15]. Thus, flavonoid glycosides are transformed into their corresponding aglycones by the action of microbiota enzymes, $\alpha$-rhamnosidases, $\beta$-glucosidases, and $\beta$-glucuronidases [16]. Then, flavonoid aglycones undergo different transformations including $C$-ring breakdown, $\alpha$-oxidation, $\beta$-oxidation, dehydrogenation, demethylation, and dehydroxylation [17]. These transformations generate a wide range of low molecular weight phenolic acids as metabolites that are structurally different and potentially more biologically active than their parent's compounds. In general, the main phenolic acid metabolites are hydroxylated forms of phenylpropionic, phenylacetic, and benzoic acids, among others. In fact, the health benefits related to the intake of flavonoids could be mainly attributed to their bioactive metabolites $[17,18]$. Thus, quercetin colonic metabolites such as 3,4-dihydroxyphenylacetic acid, 3,4-dihydroxyphenylpropionic acid, and homovanillic acid (3-methoxy-4-hydroxyphenyl acetic) have shown an antioxidant activity even higher than other antioxidant compounds such as $\alpha$-tocopherol [19]. Furthermore, 3,4-dihydroxyphenylpropionic acid (dihydrocaffeic acid), 3-(4-hydroxy-3-methoxyphenyl)propionic acid (hydroferulic acid), and 3,4-dihydroxyphenylacetic acid have been investigated by their important in vitro and in vivo anti-inflammatory effects [20]. Moreover, 3,4dihydroxybenzoic acid (protocatechuic acid) has demonstrated in vitro and in vivo properties against carcinogenesis and cardiovascular and neurodegenerative diseases [21,22].

Phenolic compounds and dietary fiber usually enter unchanged and simultaneously into the colon, being both the main substrates that lead to the formation of phenolic acids and short chain fatty acids (SCFAs), respectively, as a consequence of the catabolism of the intestinal microbiota [23,24]. The main SCFAs are acetic, butyric, and propionic acids [25]. SCFAs play an essential role in the novo synthesis of lipids and glucose in the cells, in the production of gut hormones, in the brain to regulate food intake, in the protection against enteric pathogen colonization and infection, and in the prevention and treatment metabolic diseases, among other functions [26]. Butyric and propionic acids protect against diet-induced obesity, regulate gut hormones, and reduce food intake [27]. In addition, butyric acid has been evaluated by its capacity to prevent malignant cells' formation and 
induce apoptosis in colonic cancer cells [28], and acetic acid contributes to lipogenesis in several tissues such as liver [26]. However, several studies reported that acetic acid promoted obesity via hyperphagia and insulin secretion in rodents [29], and propionic acid impaired insulin action via glucagon secretion [30].

The health-promoting effect of phenolic compounds and their microbial metabolites could be reflected in the modulation of beneficial bacteria and their metabolic activity through the increase in SCFA production. The non-absorbed phenolic compounds and their metabolites may contribute to intestinal health by modulating microbiota composition through selective prebiotic effects and antimicrobial activities against pathogenic bacteria [13]. The relationship between the phenolic metabolites and SCFA production could be associated with a possible modulation effect on carbohydrate-fermented bacteria growth [17]. However, the mechanisms by which phenolic compounds modulate the gut microbiota are still unclear. Some studies have revealed that metabolites derived from phenolic compounds (purees or as food constituents) stimulated the proliferation of beneficial bacteria such as Bifidobacterium spp. and Lactobacillus spp. and decreased that of Clostridium spp., which are considered harmful [24,31]. A balanced microbiota composition is related to maintaining good health; meanwhile, the imbalance, also called dysbiosis, is related with some health disorders such as intestinal bowel disease, irritable bowel syndrome, colorectal cancer, obesity, diabetes, metabolic syndrome, and cardiovascular disease, among others [32]. The intake of phenolic-rich sources has been proposed to prevent or even reverse the dysbiosis associated with different pathologies [33].

Although in vivo human or animal intervention trials are physiologically most relevant to study both flavonoid metabolism and microbial modulation, in vitro tools have been designed to simulate intestinal conditions because in vivo studies often imply a long time and a high cost [34]. In vitro models range from simple fermenters to highly complex models such as dynamic multistage models designed to better reproduce both human gastrointestinal digestion and the colonic fermentation process [35]. Dynamic multistage fermentation models are designed to simulate the biochemical ( $\mathrm{pH}$ changes, temperature, anaerobic conditions) and mechanical conditions (peristaltic movements, retention time, digested transit) of the whole digestion and fermentation process, as well as the metabolic conditions (microbial growth rate and substrate availability) in the different colon regions (ascending, transverse, and descending colon) [36]. These models have been applied to study the effect of foods rich in phenolic compounds on the gut microbiota metabolism [37-39].

Previous in vivo assays with Wistar rats have demonstrated that HPP-treated onion (400 MPa $/ 25^{\circ} \mathrm{C} / 5 \mathrm{~min}$ ) improved antioxidant defense mechanisms, reduced the level of hepatotoxicity, and improved the inflammatory response associated with atherogenesis in hypercholesterolemic rats. Furthermore, supplementation with the HPP-treated onion induced an increase in Lactobacillus spp. and Bifidobacterium spp., while the pathogens Clostridium spp. decreased in comparison with rats fed with normal and high-cholesterol diets [40,41].

The aim of the current study was to evaluate the impact of chronic feeding for 14 days with HPP-treated onion ( $400 \mathrm{MPa} / 25^{\circ} \mathrm{C} / 5 \mathrm{~min}$ ) on colonic metabolism using a dynamic in vitro gastrointestinal digestion and colonic fermentation (DGID-CF) simulator inoculated with the human feces of healthy volunteers. The gut metabolic activity was carried out by analyzing the flavonol compounds and their metabolites, the formation of SCFAs, and the changes in the microbial population in the different colon regions (ascending, transverse, and descending colon).

\section{Results and Discussion}

2.1. Physicochemical and Chemical Characterization and Phenolic Compounds of Undigested HPP-Treated Onion Powder

Table 1 shows the organic acids, sugars, and fiber content of the undigested HPPtreated onion powder. These data agree with other results previously published for onions by other authors [42-44]. Furthermore, Table 1 shows the phenolic compounds content 
of the undigested HPP-treated onion that was separated, identified, and quantified by high performance liquid chromatography-mass spectrometry system with a diode array detector (DAD) and coupled to an accurate-mass quadrupole time-of-flight (Agilent 6520I Accurate-Mass Q-TOF LC/MS) equipped with a jet stream dual electrospray ionization (ESI) interface (HPLC-DAD-ESI-QTOF-MS/MS) (Agilent Technologies, Santa Clara, CA, USA) according to the procedure described by Fernandez-Jalao et al. [45]. The phenolic compound composition was similar to those previously described for onions [46]. The main phenolic compounds of undigested HPP-treated onion were flavonols, and the major ones were quercetin-3,4'-di-O-glucoside (Q-3, $4^{\prime}$-diglucoside) $(75.3 \%)$, quercetin- $4^{\prime}-\mathrm{O}$ glucoside (Q-4'-glucoside) (15\%), and isorhamnetin-4'-O-glucoside (Iso- $4^{\prime}$-glucoside) $(4.8 \%)$ (Table 1). The remaining flavonols represented $5 \%$ of total flavonol content, which was $6765.16 \pm 362.27 \mu \mathrm{g} / \mathrm{g} \mathrm{dw}$. In addition, protocatechuic acid, salicylic acid, and gallic acid were identified in the HPP-treated onion at very low concentration $(\leq 2 \mu \mathrm{g} / \mathrm{g} \mathrm{dw})[44,47]$.

Table 1. Characterization and phenolic compound content of the HPP-treated onion powder.

\begin{tabular}{|c|c|}
\hline Parameters & HPP-Treated Onion \\
\hline \multicolumn{2}{|l|}{ Physicochemical characteristics } \\
\hline $\mathrm{pH}$ & $5.50 \pm 0.04$ \\
\hline Acidity (g citric acid/100 g dw) & $0.60 \pm 0.08$ \\
\hline \multicolumn{2}{|l|}{ Chemical characteristics } \\
\hline Ascorbic acid (mg/100 g dw) & $147.78 \pm 3.80$ \\
\hline Vitamin C (mg/100 g dw) & $170.60 \pm 2.57$ \\
\hline Proteins (g/100 g dw) & $3.41 \pm 0.27$ \\
\hline \multicolumn{2}{|l|}{ Fibre (mg/100 g dw) } \\
\hline Soluble & $4.57 \pm 0.15$ \\
\hline Insoluble & $14.54 \pm 0.05$ \\
\hline Total & $19.11 \pm 0.50$ \\
\hline \multicolumn{2}{|l|}{ Sugars (g/100 g dw) } \\
\hline Sacarose & $3.58 \pm 0.21$ \\
\hline Glucose & $11.95 \pm 0.75$ \\
\hline Fructose & $22.15 \pm 1.25$ \\
\hline \multicolumn{2}{|l|}{ Organic acids } \\
\hline Maleic acid (g/100 g dw) & $1.48 \pm 0.18$ \\
\hline Citric acid (mg/100 g dw) & $239.52 \pm 2.31$ \\
\hline Fumaric acid (mg/100 g dw) & $12.09 \pm 0.92$ \\
\hline Acetic acid (mg/100 g dw) & $5.21 \pm 1.32$ \\
\hline Pyruvic acid (mg/100 g dw) & $80.23 \pm 2.58$ \\
\hline \multicolumn{2}{|l|}{ Flavonols (mg/100 g dw) } \\
\hline Quercetin-3,7,4'-triglucoside & $26.74 \pm 2.39$ \\
\hline Quercetin-7,4'-diglucoside & $13.31 \pm 1.06$ \\
\hline Quercetin-3,4'-diglucoside & $5090.47 \pm 104.64$ \\
\hline Quercetin-3-rutinoside & $2.02 \pm 0.37$ \\
\hline Isorhamnetin- $3,4^{\prime}$-diglucoside & $174.46 \pm 32.23$ \\
\hline Quercetin-3-glucoside & $108.88 \pm 15.56$ \\
\hline Quercetin-4'-glucoside & $1015.55 \pm 156.38$ \\
\hline Isorhamnetin-3-glucoside & $2.04 \pm 0.31$ \\
\hline Isorhamnetin- $4^{\prime}$-glucoside & $322.77 \pm 48.46$ \\
\hline Quercetin & $5.57 \pm 0.57$ \\
\hline Isorhamnetin & $3.35 \pm 0.3$ \\
\hline \multicolumn{2}{|l|}{ Phenolic acids (mg/100 $\mathrm{g}$ dw) } \\
\hline Protocatechuic acid & $0.56 \pm 0.08$ \\
\hline Gallic acid & $1.23 \pm 0.25$ \\
\hline Salicylic acid & $1.87 \pm 0.07$ \\
\hline
\end{tabular}

Data expressed as mean $\pm \mathrm{SD}(n=4) ; \mathrm{dw}=$ dry weight; $\mathrm{HPP}=400 \mathrm{MPa} / 25^{\circ} \mathrm{C} / 5 \mathrm{~min}$. 


\subsection{Phenolic Compounds and Metabolites in the Colon Fermentation Products of HPP-Treated Onion Powder. Metabolomic Analysis by a Targeted Approach}

\subsubsection{Evolution of Flavonol Glycosides during Colonic Fermentation}

Some of the flavonol glycosides were separated, identified and quantified in the undigested HPP-treated onion powder (Table 1), as well as in the gut fermentation samples of the ascending colon (AC) (Table 2) (Figure 1) by HPLC-DAD-ESI-QTOF-MS/MS. At the initial stage of the fermentation (day 1), the major flavonols found in the fresh $\mathrm{AC}$ slurry were Q-3,4'-diglucoside (1205.88 $\pm 102 \mu \mathrm{g} / 100 \mathrm{~g}$ fw of slurry) and Q-4'-glucoside $(622.46 \pm 1.26 \mu \mathrm{g} / 100 \mathrm{~g}$ fw of slurry), which were also the major flavonols found in the undigested HPP-treated onion (Table 1). Moreover, Iso-4'-glucoside (148.65 $\pm 4.86 \mu \mathrm{g} / 100 \mathrm{~g} \mathrm{fw}$ of slurry), Iso-3,4'-diglucoside ( $92.75 \pm 6.65 \mu \mathrm{g} / 100 \mathrm{~g} \mathrm{fw}$ of slurry), and Q-3-glucoside $(59.06 \pm 2.05 \mu \mathrm{g} / 100 \mathrm{~g} \mathrm{fw}$ of slurry) were determined at the beginning of the study in the AC.

Table 2. Flavonols and phenolic metabolites identification by HPLC-DAD-ESI-QTOF-MS/MS in the fermentation products of HPP-treated onion powder subjected to a dynamic in vitro gastrointestinal digestion and colonic fermentation simulator.

\begin{tabular}{|c|c|c|c|c|c|}
\hline Compounds & Formula & Mass & $\begin{array}{c}\text { RT } \\
(\min )\end{array}$ & $\begin{array}{c}m / z \\
(\mathbf{M}-\mathbf{H})\end{array}$ & Mayor ESI $m / z[\mathbf{M}-\mathbf{H}]^{-}$and Fragments \\
\hline Benzoic acid derivatives & \multirow{3}{*}{$\begin{array}{c}\mathrm{C}_{7} \mathrm{H}_{6} \mathrm{O}_{4} \\
\mathrm{C}_{7} \mathrm{H}_{6} \\
\mathrm{O}_{5}\end{array}$} & & & & \\
\hline 3,4-Dihydroxybenzoic acid & & 154.0243 & 1.91 & 153.0193 & $153.0199 ; 133.0260 ; 109.0291 ; 91.0226 ; 81.0286$ \\
\hline 3,4,5-Trihydroxybenzoic acid (gallic acid) & & 170.0191 & 2.10 & 169.0151 & $\begin{array}{c}169.0153 ; \mathbf{1 2 5 . 0 2 2 9} ; 107.0226 ; 96.9588 ; 97.0280 ; \\
89.027 ; 68.9951\end{array}$ \\
\hline 2-Hydroxybenzoic acid (salicylic acid) & $\mathrm{C}_{7} \mathrm{H}_{6} \mathrm{O}_{3}$ & 138.0322 & 3.03 & 137.0244 & $\begin{array}{c}\text { 137.0266; } 129.0563 ; 119.0363 ; 112.9852 ; 93.0347 ; \\
89.0252 ; 68.9969\end{array}$ \\
\hline 4-Hydroxybenzoic acid & $\mathrm{C}_{7} \mathrm{H}_{6} \mathrm{O}_{3}$ & 138.0322 & 3. 29 & 137.0257 & $\begin{array}{c}137.0284 ; 124.0280 ; 112.9876 ; 108.1550 ; 98.957 ; \\
\mathbf{9 3 . 0 3 4 5}\end{array}$ \\
\hline 3,5-Dihydroxybenzoic acid & $\mathrm{C}_{7} \mathrm{H}_{6} \mathrm{O}_{4}$ & 154.0267 & 5.25 & 153.0193 & $\begin{array}{c}\text { 153.0267; } 137.0336 ; 131.0709 ; \mathbf{1 0 9 . 0 2 9 5 ; ~ 9 1 . 0 0 3 8 ; ~} \\
68.9951\end{array}$ \\
\hline \multirow{3}{*}{$\begin{array}{c}\text { 3-Hydroxybenzoic acid } \\
\text { 4-Hydroxy-3,5-dimethoxybenzoic acid } \\
\text { (syringic acid) } \\
\text { Benzoic acid }\end{array}$} & $\mathrm{C}_{7} \mathrm{H}_{6} \mathrm{O}_{3}$ & 138.0323 & 5.53 & 137.0255 & 137.0251; 123.0451; $121.0295 ; 93.0351 ; 91.0046$ \\
\hline & $\mathrm{C}_{9} \mathrm{H}_{10} \mathrm{O}_{5}$ & 198.0528 & 6.20 & 197.0455 & $\begin{array}{c}\text { 197.0458; } 187.0215 ; 161.029 ; 153.0405 ; 151.0416 ; \\
137.0319\end{array}$ \\
\hline & $\mathrm{C}_{7} \mathrm{H}_{6} \mathrm{O}_{2}$ & 122.0364 & 12.53 & 121.0294 & $121.0646 ; 102.9488 ; 89.0262 ; 77.0457$ \\
\hline \multirow{2}{*}{$\begin{array}{c}\text { Phenylacetic acid derivatives } \\
\text { 3,4-Dihydroxyphenylacetic acid } \\
\text { 3-Methoxy-4-hydroxyphenylacetic acid } \\
\text { (homovanillic acid) }\end{array}$} & $\mathrm{C}_{8} \mathrm{H}_{8} \mathrm{O}_{4}$ & 168.0425 & 2.78 & 167.0350 & $167.0343 ; \mathbf{1 2 3 . 0 4 4 7 ;} 137.0271 ; 96.4594 ; 61.9887$ \\
\hline & $\mathrm{C}_{9} \mathrm{H}_{10} \mathrm{O}_{4}$ & 182.0579 & 2.66 & 181.0506 & $\begin{array}{c}181.0584 ; 167.0358 ; \mathbf{1 3 7 . 0 3 0 5 ;} \text { 123.0461; } \\
\mathbf{1 2 2 . 0 3 5 0}\end{array}$ \\
\hline 4-Hydroxyphenylacetic acid & $\mathrm{C}_{8} \mathrm{H}_{8} \mathrm{O}_{3}$ & 152.0474 & 4.61 & 151.0407 & $\begin{array}{c}151.0534 ; 137,0281 ; 128.0355 ; \mathbf{1 2 1 . 0 2 9 5} ; \\
112.9862 ; \mathbf{1 0 7 . 0 4 9 7 ;} 96.9503\end{array}$ \\
\hline 3-Hydroxyphenylacetic acid & $\mathrm{C}_{8} \mathrm{H}_{8} \mathrm{O}_{3}$ & 152.0474 & 6.12 & 151.0407 & $\begin{array}{c}\text { 151.0406; 107.0512; 112.9861; 108.0542; } \\
119.0363 ; 65.0368\end{array}$ \\
\hline Hydroxyphenylacetic acid & $\mathrm{C}_{8} \mathrm{H}_{8} \mathrm{O}_{3}$ & 152.0474 & 7.47 & 151.0407 & 151.0422; 137.0302; 119.036; 107.0513; 89.0253 \\
\hline Phenylacetic acid & $\mathrm{C}_{8} \mathrm{H}_{8} \mathrm{O}_{2}$ & 136.0527 & 12.99 & 135.0451 & $\begin{array}{c}135.0452 ; 128.0356 ; \mathbf{1 1 7 . 2 1 0 7 ;} ; 105.0039 ; \mathbf{9 1 . 0 4 7 9 ;} \\
65.0357\end{array}$ \\
\hline $\begin{array}{c}\text { Phenylpropionic acid derivatives } \\
\text { 3,4-Dihydroxyphenylacetic acid) } \\
\text { (dihydrocaffeic acid) }\end{array}$ & $\mathrm{C}_{9} \mathrm{H}_{10} \mathrm{O}_{4}$ & 182.0579 & 4.80 & 181.0471 & 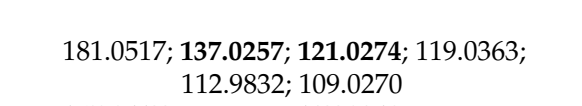 \\
\hline 3-(3-Hydroxypheny)-propionic acid & $\mathrm{C}_{9} \mathrm{H}_{10} \mathrm{O}_{3}$ & 166.0630 & 9.31 & 165.0557 & $\begin{array}{c}165.0417 ; \mathbf{1 4 7 . 3 7 1 8} ; 137.0349 ; \mathbf{1 2 1 . 0 9 0 9} \\
107.4270\end{array}$ \\
\hline 3-(4-Hydroxypheny)-propionic acid & $\mathrm{C}_{9} \mathrm{H}_{10} \mathrm{O}_{3}$ & 166.0630 & 11.79 & 165.0557 & $165.0462 ; \mathbf{1 4 8 . 3 5 6 9 ;} \mathbf{1 2 1 . 0 4 3 9 ;} 107.0339 ; \mathbf{9 2 . 8 2 8 7}$ \\
\hline \multicolumn{6}{|l|}{ Simple phenols } \\
\hline Phloroglucinol & $\mathrm{C}_{6} \mathrm{H}_{6} \mathrm{O}_{3}$ & 126.0335 & 0.77 & 125.0249 & $125.0214 ; 108.3153 ; 121.3252 ; 83.0178$ \\
\hline $\begin{array}{l}\text { Catechol } \\
\text { Hydroxycinnamic derivatives }\end{array}$ & $\mathrm{C}_{6} \mathrm{H}_{6} \mathrm{O}_{2}$ & 110.0366 & 2.66 & 109.0298 & 109.0308; 108.0225; 96.9602; 91.0153; 89.0244 \\
\hline Caffeic acid & $\mathrm{C}_{9} \mathrm{H}_{8} \mathrm{O}_{4}$ & 180.0446 & 6.20 & 179,0356 & $\begin{array}{c}179.0367 ; 161.0325 ; \mathbf{1 3 5 . 0 4 5 9 5 ;} 134.0401, \\
\mathbf{1 0 9 . 0 2 8 3 ;} \mathbf{6 1 . 9 9 0 1}\end{array}$ \\
\hline $\begin{array}{l}\text { Isoferulic acid } \\
\text { Others }\end{array}$ & $\mathrm{C}_{10} \mathrm{H}_{10} \mathrm{O}_{4}$ & 194.0579 & 16.72 & 193.0506 & $193.0515 ; 178.9886 ; 149.2177 ; 96.9549$ \\
\hline Dihydroquercetin & $\mathrm{C}_{15} \mathrm{H}_{12} \mathrm{O}_{7}$ & 304.0557 & 14,22 & 303.0510 & $\begin{array}{c}\text { 303.0528; 285.0332; 260.9191; 151.9627; } \\
\mathbf{1 2 5 . 0 2 5 4 ; 1 1 0 . 9 0 8 9}\end{array}$ \\
\hline
\end{tabular}


Table 2. Cont.

\begin{tabular}{|c|c|c|c|c|c|}
\hline Compounds & Formula & Mass & $\begin{array}{c}\text { RT } \\
(\mathrm{min})\end{array}$ & $\begin{array}{c}m / z \\
(\mathbf{M}-\mathbf{H})\end{array}$ & Mayor ESI $m / z[\mathbf{M}-\mathbf{H}]^{-}$and Fragments \\
\hline \multicolumn{6}{|l|}{ Flavonols } \\
\hline Quercetin-3,7,4'-triglucoside & $\mathrm{C}_{33} \mathrm{H}_{40} \mathrm{O}_{22}$ & 788.2041 & 13.10 & 787.1937 & $\begin{array}{c}\text { 787.1943; 770.3506; 671.1474; 625.1403; } \\
432.0439 ; 204.0667 ; 179.0487\end{array}$ \\
\hline Quercetin-7,4'-diglucoside & $\mathrm{C}_{27} \mathrm{H}_{30} \mathrm{O}_{17}$ & 626.1483 & 13.47 & 625.1404 & 625.1301; 606.1779; 463.0867; 301.0267 \\
\hline Quercetin-3, $4^{\prime}$-diglucoside & $\mathrm{C}_{27} \mathrm{H}_{30} \mathrm{O}_{17}$ & 626.1483 & 13.68 & 625.1404 & $\begin{array}{c}625.1348 ; 463.0867 ; 301.0370 ; 271.0606 ; \\
150.9868\end{array}$ \\
\hline Isorhamnetin-3,4'-diglucoside & $\mathrm{C}_{28} \mathrm{H}_{32} \mathrm{O}_{17}$ & 640.1656 & 14.34 & 639.1556 & $639.1556 ; 4777.0853 ; 313.0640 ; 303.0485$ \\
\hline Quercetin-3-rutinoside & $\mathrm{C}_{27} \mathrm{H}_{30} \mathrm{O}_{16}$ & 610.1545 & 15.34 & 609.1457 & 609.1471; 553.3327; 463.0928; 301.1196 \\
\hline Quercetin-3-glucoside & $\mathrm{C}_{21} \mathrm{H}_{20} \mathrm{O}_{12}$ & 464.0963 & 15.66 & 463.0884 & $\begin{array}{c}463.0888 ; 343.0571 ; 301.0319 ; 271.0205 ; \\
229.0334\end{array}$ \\
\hline Quercetin-4-glucoside & $\mathrm{C}_{21} \mathrm{H}_{20} \mathrm{O}_{12}$ & 464.0963 & 17.28 & 463.0881 & $463.0897 ; 445.8403 ; 301.0342 ; 283.0054$ \\
\hline Isorhamnetin-3-glucoside & $\mathrm{C}_{22} \mathrm{H}_{22} \mathrm{O}_{12}$ & 478.1122 & 17.33 & 477.1037 & $\begin{array}{c}\text { 477.1031; } 315.0414 ; 271.0043 ; 299.0117 ; \\
243.0197\end{array}$ \\
\hline Isorhamnetin-4-glucoside & $\mathrm{C}_{22} \mathrm{H}_{22} \mathrm{O}_{12}$ & 478.1122 & 18.21 & 477.1037 & $\begin{array}{c}\text { 477.1051; } 463.0893 ; 315.0393 ; 299.0150 \\
157.3284\end{array}$ \\
\hline Quercetin & $\mathrm{C}_{15} \mathrm{H}_{10} \mathrm{O}_{7}$ & 302.0381 & 19.98 & 301.0343 & $\begin{array}{c}\text { 301.0340; 273.0260; 245.0376; 178.9937; } \\
\mathbf{1 5 1 . 0 0 5 4 ; 1 2 1 . 0 3 1 3 ; 1 0 7 . 0 1 2 3}\end{array}$ \\
\hline Isorhamnetin & $\mathrm{C}_{16} \mathrm{H}_{12} \mathrm{O}_{7}$ & 316.0583 & 21.97 & 315.0501 & $\begin{array}{c}315.0508 ; 299.9147 ; 285.9066 ; 258.9187 \\
161.0463\end{array}$ \\
\hline
\end{tabular}

Bold number indicate that it is the majority fragment.
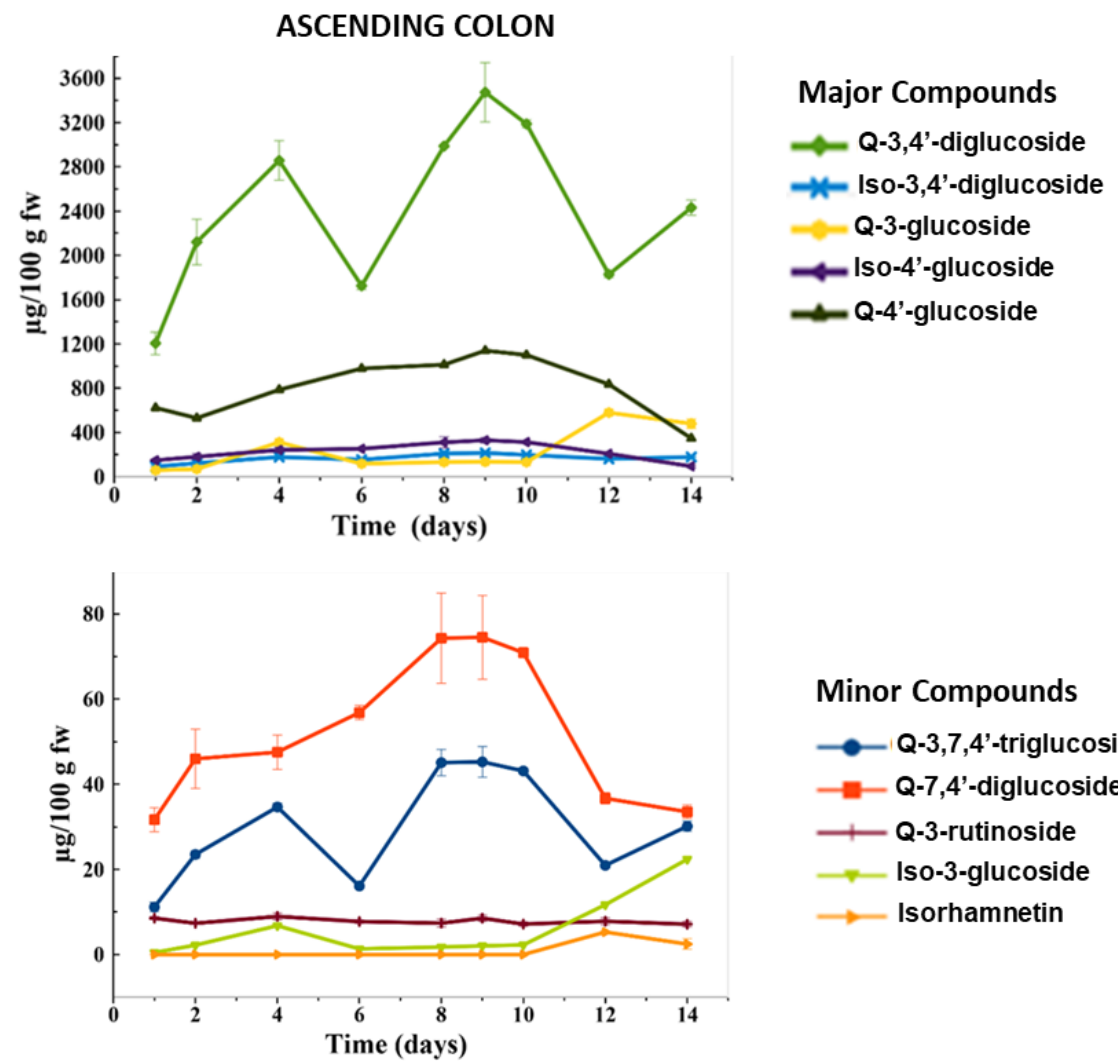

\section{Minor Compounds}

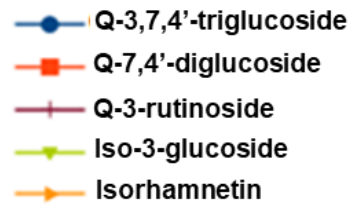

Figure 1. Concentration ( $\mu \mathrm{g} / 100 \mathrm{~g}$ fw of slurry) of flavonols in the ascending colon (AC) during the colonic fermentation of HPP-treated onion. Data are the mean value \pm standard deviation of the three different determinations $(n=3)$.

Other onion flavonols were found at concentrations lower than $30 \mu \mathrm{g} / 100 \mathrm{~g}$ fw of slurry (Q-3,7,4'-triglucoside, Q-7,4'-diglucoside, Q-3-rutinoside, Iso-3-glucoside, and Isorhamnetin aglycone). During the gut fermentation study of 14 days with the HPP-treated onion, the major flavonols (Q-3, $4^{\prime}$-diglucoside and Q-4'-glucoside) were accumulated daily in the AC slurry, reaching a maximum on day $9(3472.87 \pm 269$ and $1139.42 \pm 100 \mu \mathrm{g} / 100 \mathrm{~g}$ fw of slurry, respectively), following which they decreased their concentration progressively until the end 
of the intake period (day 14) (Figure 1). A similar trend was followed by other minor flavonols (Iso-4'-glucoside, Iso-3,4'-diglucoside and Q-7,4'-diglucoside) that also showed their maximum concentration on day 9 of the treatment period, reaching 2 times the concentration of day 1. This behavior observed for the majority of flavonol glycosides in the AC suggests that during the first 9 days of the study, the accumulation of flavonol glycosides predominated over the fermentation process. The accumulation of Q-3-glucoside and Iso-3-glucoside after 14 days of chronic feeding could be a consequence of the degradation of the major compounds Q-3,4'-diglucoside and Iso-3,4'-diglucoside, respectively, which was more intense from day 9 to the end of intake period. This behavior could also be related to the fact that some colonic bacterial species are not capable of degrading flavonols with sugar moieties at 3-O, 5-O, or 7-O position [15].

These results showed that continuous feeding with the HPP-treated onion may cause an accumulation of flavonols in the AC. This result agrees with the fact that the bioaccesibility of total flavonols in the HPP-treated onion $\left(400 \mathrm{MPa} / 25{ }^{\circ} \mathrm{C} / 5 \mathrm{~min}\right.$ ) was $17.47 \%$ (previously studied by research group) [46]. Therefore, approximately $83 \%$ of the flavonols present in the HPP-treated onion were able to reach the AC unchanged and available to be subjected to the gut microbiota metabolism [48].

The results obtained with a chronic feeding with $27 \mathrm{~g}$ per day of HPP-treated onion powder employing a DGID-CF simulator differed from those obtained from static models feeding with a single dose of phenolic compounds standards, which suffer a rapid biotransformation, disappearing from the medium within $0.5 \mathrm{~h}$ and being totally replaced by different phenolic acids that have been identified as their corresponding metabolites [24].

\subsubsection{Evolution of Flavonol Glycosides during Colonic Fermentation}

The dynamic gastrointestinal digestion-colon fermentation (DGID-CF) system was fed every day with $27 \mathrm{~g}$ of HPP-treated onion powder representing, a daily intake of $150.39 \mu \mathrm{g}$ of quercetin aglycone according to its initial content (Table 3).

Table 3. Daily quercetin (Q) supply and evolution during a dynamic in vitro colonic fermentation of HPP-treated onion powder.

\begin{tabular}{ccc}
\hline & & Daily Quercetin Supply $(\boldsymbol{\mu g})$ \\
\hline & & 134.64 \\
\hline Colon Region & Days & Quercetin $(\boldsymbol{\mu g} / \mathbf{1 0 0} \mathbf{g}$ fw of Slurry) \\
\cline { 2 - 3 } AC $^{1}$ & $4 \mathrm{~d}$ & $360.22 \pm 18.82^{\mathrm{b}}$ \\
\cline { 2 - 3 } & $9 \mathrm{~d}$ & $118.51 \pm 13.44^{\mathrm{a}}$ \\
\cline { 2 - 3 } & $14 \mathrm{~d}$ & $529.73 \pm 68.79^{\mathrm{c}}$ \\
\cline { 2 - 3 } TC $^{1}$ & $4 \mathrm{~d}$ & $5.24 \pm 1.74^{\mathrm{b}}$ \\
& $9 \mathrm{~d}$ & $1.70 \pm 0.28^{\mathrm{a}}$ \\
\hline & $14 \mathrm{~d}$ & $10.10 \pm 0.51^{\mathrm{c}}$ \\
\cline { 2 - 3 } DC $^{1}$ & $4 \mathrm{~d}$ & $0.89 \pm 0.21^{\mathrm{a}}$ \\
& $9 \mathrm{~d}$ & $1.54 \pm 0.2^{\mathrm{a}}$ \\
\cline { 2 - 3 } & $14 \mathrm{~d}$ & $2.37 \pm 1.03^{\mathrm{a}}$
\end{tabular}

${ }^{1}$ Colon fermentation products were collected in the AC (ascending colon), TC (transverse colon), and DC (descending colon) at day 4,9 , and 14 of the fermentation studies. Data ( $\mu \mathrm{g} / 100 \mathrm{~g}$ fw of slurry) are expressed as mean \pm standard deviation. Different small letters indicate significant differences $(p<0.05)$ between different sample collection days for the HPP-treated onion and colon regions (AC, TC, and DC).

After gastrointestinal digestion and taking into account quercetin bioaccessibility $(10.47 \%)$ in the HPP-treated onion determined in previous studies [46], the amount of quercetin that reached the colon unaltered could be much less, about $134.64 \mu \mathrm{g}$ per day $(89.53 \%$ of $150.39 \mu \mathrm{g})$ (Table 3$)$. This low amount of quercetin that fed the colon daily was not consistent with the high quercetin concentration found in the AC (Table 3), which 
could be most related to the deglycosylation of quercetin glycosides by gut microbiota [5]. Contrary to that observed for quercetin glycosides, quercetin aglycone was also present in the transverse colon (TC) and descending colon (DC), but in a significantly lower concentration (Table 3).

These results show that the deglycosylation of quercetin glycosides, probably catalyzed by gut microbial enzymes such as $\beta$-glucosidases, $\beta$-glucuronidases, and $\alpha$-rhamnosidases [16], took place with greater intensity in the AC than in the TC and DC, resulting in the quercetin aglycone being released. The very low concentration of quercetin aglycone found in the TC and DC could indicate that in these two regions of the colon, the degradation of quercetin aglycone by the gut microbiota predominates. In general, a quick deglycosylation of quercetin glycosides has been described in different plant-derived foods submitted to fecal fermentation using static models. Thus, quercetin glycosides from green pepper, mainly quercetin-3-rhamnoside, were quickly metabolized in the first minutes of fecal fermentation while accumulating quercetin in high concentration, reaching the maximum concentration after $5 \mathrm{~h}$ [49]. Moreover, quercetin glycosides from apples, mainly quercetin-3-glucoside and quercetin-3-rhamnoside, were completely transformed in quercetin aglycone after $24 \mathrm{~h}$ of the fecal fermentation of apples [23]. These results agree with the fact that the quercetin deglycosylation may occur at different rates depending on its concentration [50], sugar moiety [16], and inter-individual variation of the microbiota profile [51]. Thus, the food matrix could modulate the interaction of the phenolic compound with the gut microbiota [17,52].

The use in the present study of a dynamic fermentation model system that was continuously fed with the HPP-treated onion allowed the presence of great amounts of quercetin aglycone during the 14 days of the study, which promotes important health-protective characteristics to the colon, mainly in the AC. Quercetin presented great antioxidant power against reactive oxygen species and free radicals, and the capacity to inhibit pro-oxidant enzymes (lipoxygenase, xanthine oxidase, NADPH oxidase) [7]. Moreover, quercetin has shown cardioprotective effects related to its anti-inflammatory activity, capacity of inhibition of LDL and oxidation and reduction of adhesion molecules, platelet antiaggregating, and vasodilator effects $[8,9]$.

\subsubsection{Evolution of Flavonol Metabolites during Colonic Fermentation}

In general, the gut microbiota metabolism of phenolic compounds involves numerous reactions (hydrolysis, hydrogenation, $\alpha$ - and $\beta$-oxidation, demethoxylation, dehydroxylation, and decarboxylation) that result in the formation of a wide range of metabolites [18]. The non-bioaccessible flavonol glycosides of the HPP-treated onion that reached the ascending colon $(\mathrm{AC})$ unchanged after the gastrointestinal digestion suffered firstly a deconjugation catalyzed by fecal microbiota enzymes (ß-glucosidase, $\alpha$-rhamnosidase, and $ß$-glucuronidase), releasing the quercetin aglycone that was then extensively degraded by the colon microbiota to produce a wide range of metabolites, mainly phenolic acids.

A total of 23 phenolic metabolites were identified by HPLC-DAD-ESI-QTOF-MS/MS (Table 2) and were targeted during the different regions of the gut fermentation dynamic model feeding for 14 days with the intestinal digestion fraction of the HPP-treated onion. In decreasing order of concentration by families, derivatives of phenylacetic acids, phenylpropionic acids, benzoic acids, and others were identified (Table 2). Some of these microbial metabolites appeared in the ascending colon (AC) even if they were found in higher concentration in the transverse colon (TC) and descending colon (DC), along with the disappearance of parent phenolic compounds. The evolution of phenolic compound metabolites, described by families, during the feeding intake period with $27 \mathrm{~g}$ of HPP-treated onion (once a day for 14 days) in the three colon regions, ascending colon (AC), transverse colon (TC), and descending colon (DC), is shown in Figure 2 and described below. 

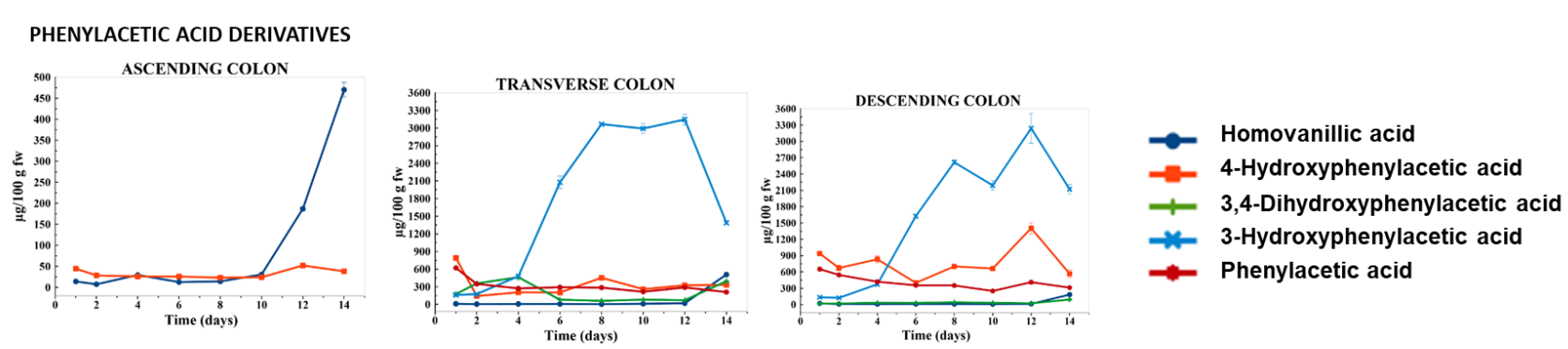

PHENYLPROPIONIC ACID DERIVATIVES
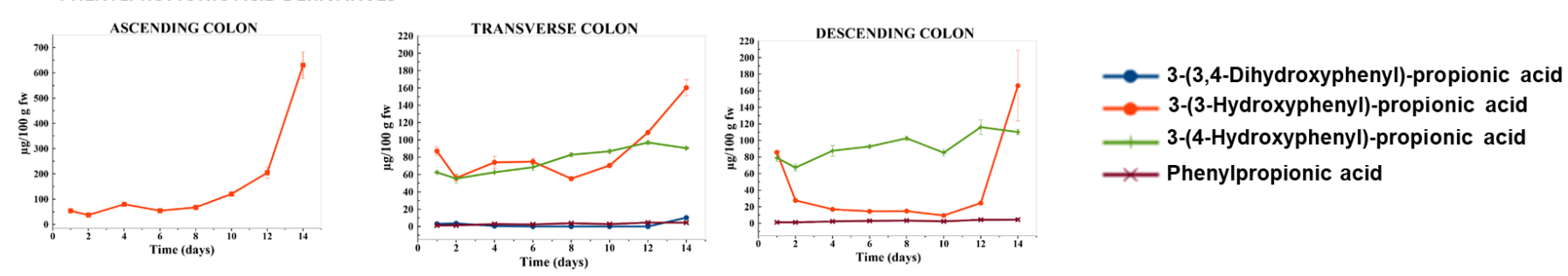

BENZOIC ACID DERIVATIVES
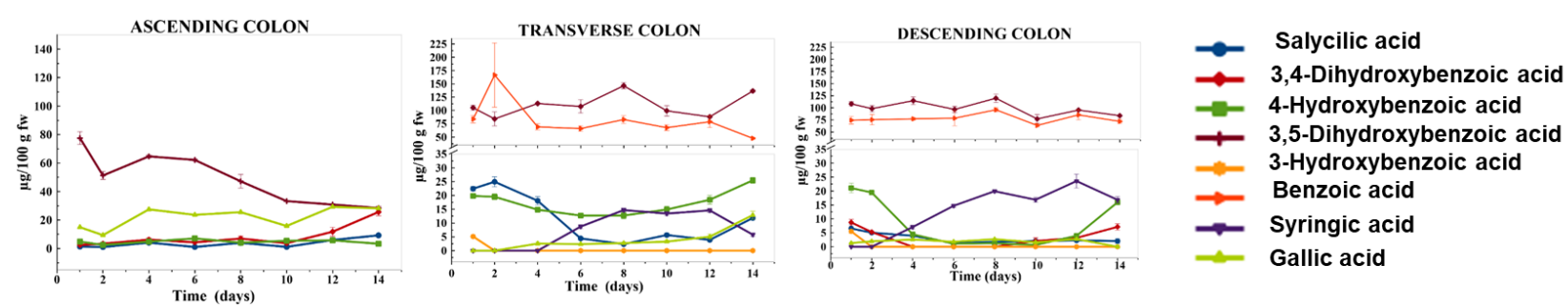

Figure 2. Concentration ( $\mu \mathrm{g} / 100 \mathrm{~g} \mathrm{fw}$ of slurry) of phenylacetic, phenylpropionic, and benzoic acid derivatives, in the ascending colon (AC), transverse colon (TC), and descending colon (DC) during the colonic fermentation of HPP-treated onion powder. Data are the mean values \pm standard deviation of three different determinations $(n=3)$.

Phenylacetic acid derivatives. This group belongs to the major metabolite found in the present study: 3-hydroxyphenylacetic acid. Aside from this metabolite, the concentration of 3,4-dihydroxyphenylacetic acid, 4-hydroxyphenylacetic acid, homovanillic acid (3-methoxy-4-hydroxyphenylacetic acid), 2-hydroxyphenylacetic acid (tentatively identified), and phenylacetic acid in the three regions (AC, TC, and DC) of the gut fermentation dynamic model fed with the HPP-treated onion for 14 days were shown in Figure 2.

3,4-Dihydroxyphenylacetic acid was not detected in the AC, but in TC and DC, it was found in increasing concentration from day 1 (176.08 and $18.75 \mu \mathrm{g} / 100 \mathrm{~g}$ fw of slurry, respectively) to a peak content on day 4 in both regions (462.66 and $136.47 \mu \mathrm{g} / 100 \mathrm{~g} \mathrm{fw}$ of slurry, respectively), remaining stable afterwards (Figure 2).

In addition, 3-hydroxyphenylacetic acid, formed by dehydroxylation from 3,4-dihydroxyp henylacetic acid was not found in the AC, but the concentration of this metabolite increased progressively from day 1 to day 8-10, reaching a peak concentration of approximately $3000 \mu \mathrm{g} /$ $100 \mathrm{~g} \mathrm{fw}$ in TC and $2700 \mu \mathrm{g} / 100 \mathrm{~g}$ fw in the DC (Figure 2). This result agrees with previous studies that showed 3-hydroxyphenylacetic acid as the major metabolite of quercetin submitted to an in vitro static fermentation process [24].

However, 4-hydroxyphenylacetic acid, also formed from 3,4-dihydroxyphenylacetic acid, was found in AC, TC, and DC. The AC presented a low concentration (average of $25 \mu \mathrm{g} / 100 \mathrm{~g} \mathrm{fw}$ ) of slurry during most of the fermentation process (Figure 2). The concentration of this metabolite significantly increased at day 1 in the TC $(790.51 \pm 16.81 \mu \mathrm{g} /$ $100 \mathrm{~g}$ fw of slurry) and DC (939.45 $\pm 8.54 \mu \mathrm{g} / 100 \mathrm{~g}$ fw of slurry), and then descended in successive days until day 12 , reaching peak concentration in the two colon regions (939.45 \pm 8.54 and $1406.1 \pm 4.97 \mu \mathrm{g} / 100 \mathrm{~g}$ fw in TC and DC, respectively) (Figure 2).

Another metabolite tentatively identified as 2-hydroxyphenylacetic, which could be formed from 3- and 4-hydroxyphenylacetic acids, showed a peak concentration at day $1 \mathrm{in}$ the AC $(84.84 \pm 6.96 \mu \mathrm{g} / 100 \mathrm{~g} \mathrm{fw})$, TC $(776.34 \pm 21.96 \mu \mathrm{g} / 100 \mathrm{~g} \mathrm{fw})$, and DC 
$(848.33,33 \pm 29.99 \mu \mathrm{g} / 100 \mathrm{~g} \mathrm{fw})$. A decrease of $48 \%$ at day 2 in comparison to day 1 was observed in the three regions of the colon reaching an average concentration of 48, 387, and $420 \mu \mathrm{g} / 100 \mathrm{~g} \mathrm{fw}$ in the AC, TC and DC, respectively, from day 3 to day 14 of the intake period (Figure 2).

Phenylacetic acid was only detected in the TC and DC, showing a decreasing trend from day 1 to day 14 (Figure 2). This behavior indicated that this metabolite could be present in the initial fecal samples before the chronic feeding with HPP-treated onion as a result of the metabolism of the gut microbiota. Similar results were found by other authors that studied a chronic feeding of a gut fermentation model system with grape pomace [53].

3-Methoxy-4-hydroxyphenylacetic acid (homovanillic acid) was found in the three colon regions but in low concentration $(<30 \mu \mathrm{g} / 100 \mathrm{~g} \mathrm{fw})$ during 11 days of the intake period. From day 11 to 14, a significant increase of 15, 50, and 24 times the concentration in the AC, TC, and DC, respectively, was observed.

Phenylacetic acid derivatives have been found in the three regions of the colon, specifically di- and mono-hydroxylated phenylacetic acids, which have been described as the main gut microbial metabolites from quercetin and quercetin glycosides $[5,16]$. The degradation pathway of quercetin starts with the formation of dihydroquercetin, which is further degraded into 3-(3,4-dihydroxyphenyl)-propionic (both identified in the present study), followed by a C-ring fission. Successive degradations form the 3,4-dihydroxyphenylacetic acid, which may be dehydroxylated to monohydroxyphenylacetic acids and phenylacetic acids, or methylated to form homovanillic acid [5,17]. Phenylacetic acids derivatives have also been identified as metabolites of other flavonoids (i.e., flavan-3-ols), but not as main metabolites [24,54].

Phenylpropionic acid derivatives. The major metabolite of this group was 3-(3hydroxyphenyl)-propionic acid, which was in the three regions of the colon in a stable concentration in AC $(\sim 58 \mu \mathrm{g} / 100 \mathrm{~g}$ fw of slurry $), \mathrm{TC}(\sim 76 \mu \mathrm{g} / 100 \mathrm{~g}$ fw of slurry $)$, and DC ( $\sim 18 \mu \mathrm{g} / 100 \mathrm{~g}$ fw of slurry) during the first 8 days of the study (Figure 2$)$. The concentration of this metabolite significantly increased from day 10 to day 14 , reaching a maximum in the AC $(629.28 \pm 51.95 \mu \mathrm{g} / 100 \mathrm{~g}$ fw of slurry), TC $(160.22 \pm 9.33 \mu \mathrm{g} / 100 \mathrm{~g}$ fw of slurry $)$, and DC (166.07 $\pm 42.6 \mu \mathrm{g} / 100 \mathrm{~g}$ fw of slurry) (Figure 2$)$.

Moreover, 3-(4-hydroxyphenyl)-propionic acid was found in the TC at a similar concentration to 3-(3-hydroxyphenyl)-propionic acid during most days of chronic feeding with HPP-treated onion (Figure 2). However, 3-(4-hydroxyphenyl)-propionic acid was the major compound in the DC and its concentration increased from day $1(\sim 78 \mu \mathrm{g} / 100 \mathrm{~g}$ fw of slury) to day $14(\sim 100 \mu \mathrm{g} / 100 \mathrm{~g}$ fw of slurry) (Figure 2$)$. These two metabolites were formed from 3-(3,4-dihydroxyphenyl)-propionic acid that was detected in the TC at the end of the intake period but in very low concentration $(10.21 \mu \mathrm{g} / 100 \mathrm{~g} \mathrm{fw}$ of slurry) (Figure 2). This compound could be dehydroxylated and transformed to 3-(4hydroxyphenyl)-propionic acid and 3-(3-hydroxyphenyl)-propionic acid, and this last could have suffered a subsequent transformation to produce 3-hydroxyphenylacetic acid, the most abundant metabolite found in the present study, mainly observed in the TC and DC (Figure 2).

Phenylpropionic acid derivatives are common metabolite products of the degradation pathways of different phenolic compound families in addition to flavonoids. Thus, after the deconjugation of flavonoids and subsequent aglycones release and de-esterification of phenolic acids, latter transformations (i.e., dehydroxylation, reduction, and C-ring fission) allow the formation of phenylpropionic acid derivatives $[17,18]$.

Benzoic acid derivatives. The benzoic acid derivatives identified could be divided into two groups: the majority, a dihydroxybenzoic acid tentatively identified as 3,5dihydroxybenzoic acid (Table 2) and benzoic acid; and the minority, such as 3,4,5-trihydroxy benzoic acid (gallic acid), 3,4-dihydroxybenzoic acid (protocatechuic acid), 4-hydroxybenzoic acid, 2-hydroxybenzoic acid (salicylic acid), and 4-hydroxy-3,5-dimethoxybenzoic acid (syringic acid) (Figure 2). 
The most abundant benzoic acid found in the AC, TC, and DC of the present study was 3,5-dihydroxybenzoic acid followed by benzoic acid but mainly in the TC and DC (Figure 2). The concentration of 3,5-dihydrozybenzoic acid decreased approximately $64 \%$ in the AC from day $1(77.53 \pm 4.43 \mu \mathrm{g} / 100 \mathrm{~g}$ fw of slurry) to day $14(28.44 \pm 41.21 \mu \mathrm{g} / 100 \mathrm{~g}$ fw of slurry), while 3,4-dihydroxybenzoic acid (protocatechuic acid) increased from day $1(2.48 \mu \mathrm{g} / 100 \mathrm{~g} \mathrm{fw}$ of slurry) to day $14(25 \mu \mathrm{g} / 100 \mathrm{~g} \mathrm{fw})$. In the TC and DC, 3,4dihydroxybenzoic acid was detected but in a very low concentration $(<8 \mu \mathrm{g} / 100 \mathrm{~g} \mathrm{fw}$ of slurry). 3,5-Dihydrozybenzoic acid and benzoic acid were the major metabolites of this group, with a peak level on day 8 in TC (146.56 and $82.87 \mu \mathrm{g} / 100 \mathrm{~g}$ fw of slurry, respectively) and in DC (119.74 and $95.96 \mu \mathrm{g} / 100 \mathrm{~g}$ fw of slurry), respectively.

4-Hydroxybenzoic acid was more abundant in the TC than in AC and DC and its concentration was relatively stable (average $22.5 \mu \mathrm{g} / 100 \mathrm{~g} \mathrm{fw}$ ) during the 14 days of the intake period (Figure 2). This compound showed an irregular evolution during fermentation in the three colon regions.

Gallic acid was found in the three colon regions, especially in the AC. Gallic acid is a common phenolic compound in vegetables, and its accumulation in the AC could also be related to the presence of this compound in the initial fecal product before feeding the system with HPP-treated onion, due to this acid being the end product of the gut fermentation of different phenolic families such as gallotannins.

3,4-Dimethoxybenzoic acid (syringic acid) that was detected in the TC and DC from day 4 to 14 could be formed from gallic acid by the action of gut bacteria enzymes [55].

2-Hydroxybenzoic acid (salicylic acid) was observed in the HPP-treated onion, albeit at low concentrations ( $1.87 \mu \mathrm{g} / 100 \mathrm{fw}$ of slurry), but in the fermentation products, a trend of its content increasing was observed in the AC. However, in the TC and DC, salicylic acid content was stable or instead decreased towards the end of the study. Moreover, salicylic acid has been observed after the fermentation of an extract of grape and cranberry with gut microbiota [38]. However, contrary to our results, the increase of salicylic acid was observed towards the end of the incubation period $(48 \mathrm{~h})$ in the DC.

Benzoic acid derivatives are amongst the end-products of the metabolism of phenolic compounds due to the gut microbiota [21,54]. 3,4-Dihydroxybenzoic acid could be formed through the B-ring degradation of some phenolic compounds such as anthocyanins or quercetin [21,47]. In addition, 3,4-dihydroxyphenylacetic acid generated from the catabolic pathways of different phenolic compounds could be degraded into 3,4-dihydroxybenzoic acid (protocatechuic acid), and finally into benzoic acid [17,56].

Other metabolites. Two simple phenolic compounds were identified and quantified in the three colonic fermentation regions: catechol and phloroglucinol. The concentration of phloroglucinol was higher in the $\mathrm{AC}$, mainly during the first 8 days of the intake period $(\sim 350 \mu \mathrm{g} / 100 \mathrm{~g}$ fw of slurry) than in the TC (average $74 \mu \mathrm{g} / 100 \mathrm{~g} \mathrm{fw}$ of slurry) and DC (average $62 \mu \mathrm{g} / 100 \mathrm{~g}$ fw of slurry). In general, phloroglucinol resulted from an end-product from the metabolism of quercetin and other compounds such as procyanidins, chalcones, and dihydrochalcones $[18,56,57]$. In the case of HPP-treated onion, phloroglucinol could be one of the end metabolites of flavonols with hydroxyl groups at position 5 and 7 of the A-ring [54]. Catechol was quantified during the entire intake period in the three colon regions in both ingredients. The concentration was similar between the AC, TC, and DC in both ingredients. Catechol could be formed by the decarboxylation of protocatechuic acid (3,4-dihydroxybenzoic acid) [58].

Furthermore, dihydroquercetin was detected at the end of the intake period in the AC and TC. This compound, also called taxifolin, has been described as an initial metabolite formed from quercetin which could be further metabolized to di- and monohydroxyphenylpropionic acids [17].

Total flavonol metabolites. The evolution of total flavonol metabolite content identified in the three colon regions during chronic feeding with HPP-treated onion is shown in Figure 3. The flavonol metabolites were mainly formed in the TC and DC and their concentration was between 3 and 4 times higher than in the AC. During the 14 days of 
the chronic feeding study, the total metabolites content increased from day 2 to a maximum concentration at day 12 in TC (4779.34 $\pm 179 \mu \mathrm{g} / 100 \mathrm{~g}$ fw of slurry) and in DC $(5910.61 \pm 165 \mu \mathrm{g} / 100 \mathrm{~g}$ fw of slurry) which represented an increase of 2.5 times the initial concentration (Figure 3).

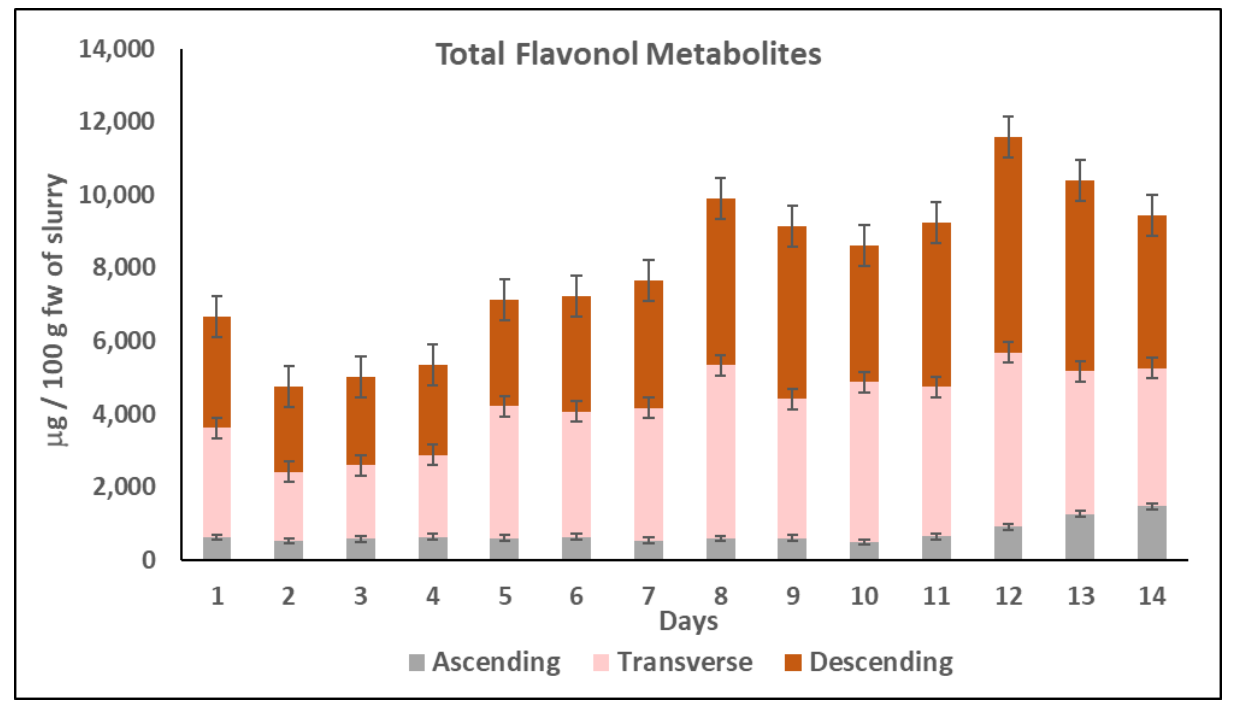

Figure 3. Total flavonols metabolites ( $\mu \mathrm{g} / 100 \mathrm{~g}$ fw of slurry) in the ascending colon (AC), transverse colon (TC), and descending colon (DC) during the colonic fermentation of HPP-treated onion. Data are the mean values \pm standard deviation of three different determinations $(n=3)$.

Different health-promoting effects of some of the flavonol metabolites found in the gut fermentation products of HPP-treated onion in the current study have been previously described. Thus, 3,4-dihydroxyphenylacetic acid has shown in vitro and in vivo antiproliferative [59], hepatoprotective [60], anti-inflammatory [61], and antioxidant properties [62]. In addition, 3-(3-hydroxyphenyl)-propionic acid has shown its potential as a vasodilator, even more than quercetin [63]. In fact, this HPP-treated onion powder (400 $\mathrm{MPa} / 25^{\circ} \mathrm{C} / 5 \mathrm{~min}$ ) supplied as a supplement in the diet of hypercholesterolemic Wistar rats for 7 weeks demonstrated antioxidant, anti-inflammatory, hepatoprotective properties and the capacity to prevent or partially modulate vascular dysfunction by reducing some of the risk indexes linked to the initial stages of atherosclerosis $[40,41]$. These health-promoting properties of the HPP-treated onion ingredient demonstrated by in vivo assays with rats could be related with the formation in the gut of the different metabolites described in the present study, such as 3,4-dihydroxyphenylacetic acid mainly found in the TC and DC, although it was quickly metabolized to 3-hydroxyphenylacetic resulting in the major metabolite (Figure 2). In general, the different phenolic metabolites profile in the three colon regions (AC, TC, DC) could be attributable to different microbiota composition among them [64].

\subsubsection{Multivariate Data Analysis of the HPLC-DAD-ESI-QTOF-MS/MS Data}

Based on a total of 34 features found by the LC/MS negative ionization mode of the HPP-treated onion colonic fermentation samples, among which 11 were phenolic compounds precursors and 23 were phenolic metabolites (Table 2), a PCA model was built showing a clear separation of components into three different clusters, indicating a different composition in phenolic compounds and in their corresponding metabolites at each of the three regions of the colon (Figure 4). Data variability was mainly given by the first component (PC1) (63.8\%). The multivariate model showed good quality in terms of variance explained $\left(R_{2}=0.934\right)$ and variance predicted $\left(Q_{2}=0.921\right)$. 


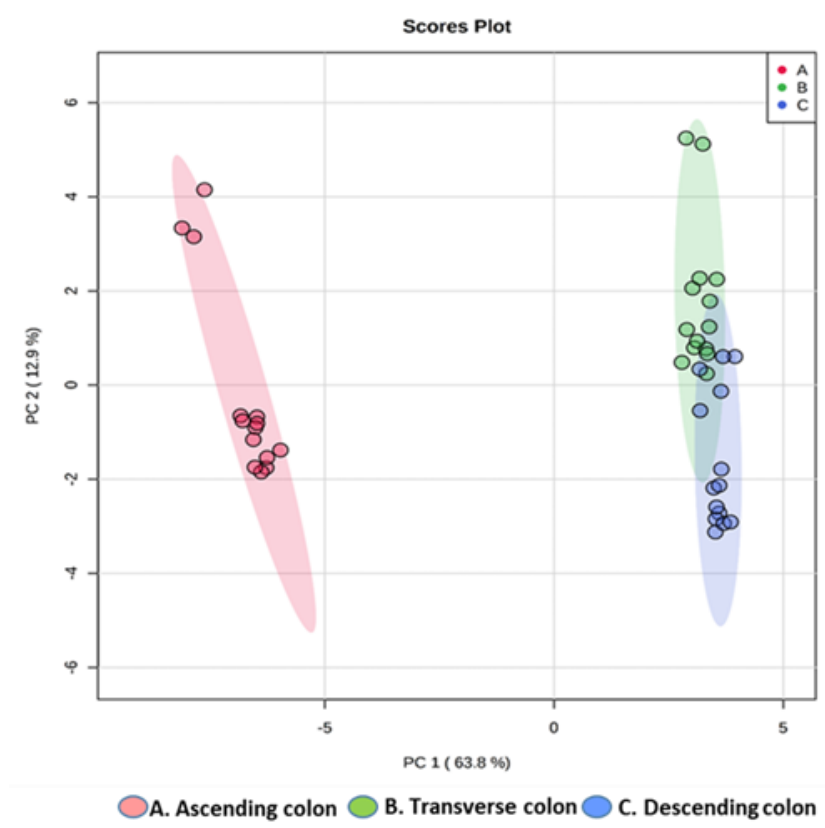

Figure 4. Principal component analysis (PCA) score plot of HPP-treated onion fermentation products. The parameters for these models were: $\mathrm{R} 2=0.934, \mathrm{Q} 2=0.921$. A Student's t-test at $95 \%$ level $(p<0.05)$ was used to select the most important variables in each model.

\subsection{Modulation of Microbiota Population}

A bidirectional relation between phenolic compounds and microbiota has been suggested based on the role of colon microbiota in the metabolism of phenolic compounds and at the same time the influence of phenolic metabolites in the microbiota composition [65]. Thus, the influence of HPP-treated onion on gut microbiota population was evaluated by using microbiological counts methods, although more accurate molecular methods such as quantitative PCR and fluorescence in situ hybridization (FISH) with ribosomal RNA-targeted oligonucleotide probes exist. The colon microbial population analyzed was Enterobacteriaceae and anaerobic bacteria as indicators of total colon microbiota, Bifidobacterium spp. and Lactobacillus spp. considered beneficial bacteria, and Clostridium spp. and total coliforms as potential harmful colon bacteria (Figure 5).

The anaerobic bacteria content was stable in the three colon regions (AC, TC, DC) during the 14 days of feeding the gastrointestinal-colon fermentation system with the HPP-treated onion. A decrease of Enterobacteriaceae of $1.5 \log \mathrm{CFU} / \mathrm{mL}$ in the AC compared to the baseline concentration was observed after the 14 days of the chronic feeding while remaining stable in the TC and DC (Figure 5). In addition, the level of Clostridium spp. decreased in the three colon regions, being more remarkable in the $\mathrm{AC}(\sim 1.5 \log \mathrm{CFU} / \mathrm{mL})$. Furthermore, a decrease of total coliforms in the AC $(1.5 \mathrm{CFU} / \mathrm{mL})$ was observed meanwhile remained stable in the TC and DC (Figure 5). 

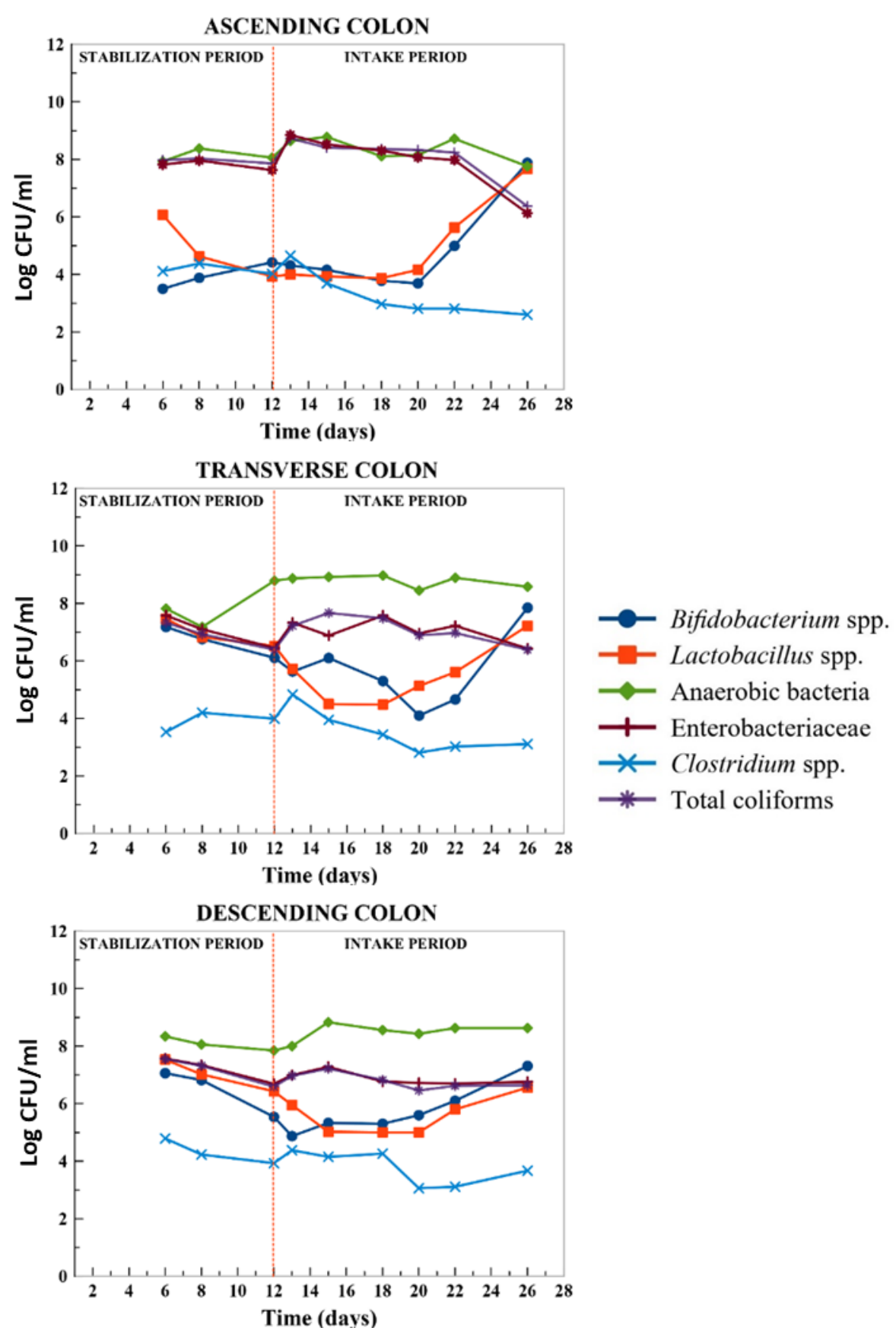

Figure 5. Changes in bacterial populations in the AC (ascending colon), TC (transverse colon), and DC (descending colon) during the stabilization period and intake period with HPP-treated onion: days 0 (13), day 2 (15), day 5 (18), day 7 (20), day 9 (22), and day 13 (26). Results are expressed as log $\mathrm{CFU} / \mathrm{mL}(n=2)$.

With respect to the beneficial bacteria population, Bifidobacterium spp. and Lactobacillus spp. increased in the three colon regions and the major increment was observed in the AC after the first 4 days of feeding the system with HPP-treated onion ( 3 and $3.5 \log \mathrm{CFU} / \mathrm{mL}$, respectively) (Figure 5).

Therefore, HPP-treated onion seemed to favor the microbiota composition balance through the increase in Bifidobacterium spp. and Lactobacillus spp. and a tendency to decrease the level of Enterobacteria, total coliforms, and Clostridium spp. Different studies have suggested that phenolic compounds supplied through different dietary sources and 
their corresponding colonic bacterial metabolites may exert selective prebiotic effects and antimicrobial activities against gut pathogenic bacteria [13,65].

In a study by Duque et al. [66], treatment with fresh and pasteurized orange juice allowed the increase of $1 \log$ CFU of Bifidobacterium spp. and Lactobacillus spp. in the three colon regions using the SHIME, an in vitro dynamic fermentation model. In addition, Bifidobacterium spp. increased significantly $(p<0.05)$ after the batch-culture fermentation of fresh 'Renetta Canada' and 'Golden Delicious' apples compared to cellulose and to a greater extent than the increase observed after inulin (a known prebiotic) administration [23]. The reduction of Enterobacteria and Clostridium spp. populations by several phenolic compound food sources has been reported. A significant reduction in the Enterobacteriaceae population was observed in the ascending and descending colon after the in vitro fermentation of cranberry and grape seed extract [38]. On the other hand, an intervention study of flavan3-ols in cocoa (catechin and epicatechin) in healthy volunteers limited the growth of the Clostridium histolyticum group [31]. Moreover, a red wine extract subjected to an in vitro fermentation process showed a slight inhibition of the Clostridium histolyticum group [67].

The increase of Bifidobacterium spp. and Lactobacillus spp. after chronic feeding with HPP-treated onion observed in the present study could be related with the accumulation of the major metabolites in the fermentation products derived from quercetin glycosides, such as 3,4-dihydroxyphenylacetic rapidly transformed to 3-hydroxyphenylacetic acid, and other monohydroxy-phenylacetic acids. Other authors have found significant increases of $61 \%$ and $35 \%$ in the proliferation of Bifidobacterium longum after the fermentation of quercetin and 3-hydroxyphenylacetic acid, respectively, by the gut microbiota [24]. It is important to highlight the high concentration of non-digestible dietary fiber of the HPPtreated onion (19.11 $\pm 0.50 \mathrm{mg} / 100 \mathrm{~g} \mathrm{dw}$ ) (Table 1) that reaches the colon and could be another important factor that modulates the gut microbial growth.

\subsection{Short-Chain Fatty Acids (SCFAs) Content}

The impact of chronic feeding with HPP-treated onion on colon microbiota activity using the DGID-CF simulator can be also evaluated by observing the formation of SCFAs. The main SCFAs found were acetic acid (C2:0), propionic acid (C3:0), and butyric acid (C4:0) (Figure 6), and they represented more than $95 \%$ of total fatty acids analyzed. Other minor fatty acids determined were isobutyric acid (iso C4), valeric acid (C5:0), caproic acid (C6:0), and heptanoic acid (C7:0). The individual and total SCFAs content was higher in the TC and $\mathrm{DC}$ than in the $\mathrm{AC}$. The total concentration increased progressively in the three colon regions $(\mathrm{AC}, \mathrm{DC}, \mathrm{TC})$ during the intake period reaching a peak of total concentration at day 10 in the AC (1506.87 $\pm 17.78 \mu \mathrm{mol} / 100 \mathrm{~g} \mathrm{fw})$ and DC $(10143.71 \pm 1150 \mu \mathrm{mol} / 100 \mathrm{~g} \mathrm{fw})$, while in the TC, total peak concentration was achieved at day $12(5695.18 \pm 131.13 \mu \mathrm{mol} / 100 \mathrm{~g} \mathrm{fw})$ (Figure 6).

The lowest concentration of total SCFA was found in the ascending colon (AC) during the 14 days of the study (Figure 6) with acetic acid being the major SCFA followed by propionic acid. Both acetic and propionic acid content increased progressively during the chronic feeding with HPP-treated onion from day $0(117.38 \pm 9.02$ and $45.43 \pm 6.14 \mu \mathrm{mol} / 100 \mathrm{~g} f w$, respectively) to day $10(1279 \pm 0.21$ and $228.59 \pm 17.55 \mu \mathrm{mol} / 100 \mathrm{~g} \mathrm{fw}$, respectively) in the AC (Figure 6).

In the TC and DC, in addition to acetic and propionic acid, butyric acid was also detected as one of the main SCFAs in the TC from day 6 to day 10 of the assay and its concentration was approximately $40 \%$ and $58 \%$ higher than acetic and propionic acids, respectively (Figure 6). In the DC, the major compound during the 14 days of intake period was acetic acid, while not significant differences were found between butyric and propionic acid content (Figure 6). 

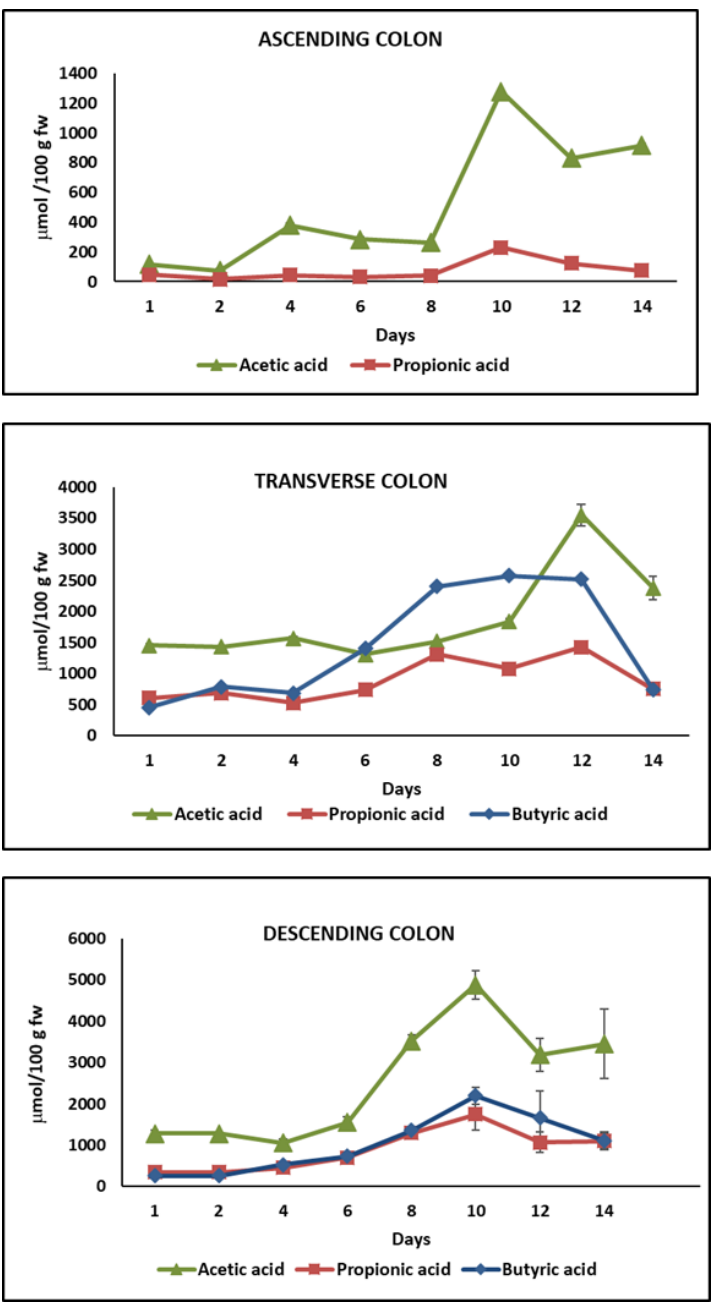

Figure 6. Concentration ( $\mu \mathrm{mol} / 100 \mathrm{~g}$ fw of slurry) of the main short-chain fatty acids (SCFAs) in the ascending colon (AC), transverse colon (TC), and descending colon (DC) during the colonic fermentation of HPP-treated onion. Data are the mean values \pm standard deviation of three different determinations $(n=3)$.

The concentration of the three SCFAs increased progressively during the intake period, reaching peak concentration at day 10 where the content of acetic acid (4853.89 $\pm 347 \mu \mathrm{mol} /$ $100 \mathrm{~g} \mathrm{fw})$, butyric acid $(2197.93 \pm 382 \mu \mathrm{mol} / 100 \mathrm{~g} \mathrm{fw})$, and propionic acid (1747.19 $\pm 202 \mu \mathrm{mol} /$ $100 \mathrm{~g} \mathrm{fw}$ ) was 4, 5, and 8 times higher, respectively, than their concentration at day 0 (Figure 6).

Therefore, chronic feeding with HPP-treated onion resulted in a significant increase of total SCFAs with a peak level at day 10 in the three colon regions: AC $(1506.88 \pm 17.8 \mu \mathrm{mol} / 100 \mathrm{~g}$ $\mathrm{fw}$ of slurry), TC (5695.18 $\pm 131 \mu \mathrm{mol} / 100 \mathrm{~g}$ fw of slurry), and DC (10,143.71 $\pm 1150 \mu \mathrm{mol} /$ $100 \mathrm{~g} \mathrm{fw}$ of slurry) (Figure 7), with acetic and propionic acid being the major SCFAs in AC and DC, while butyric acid was the major SCFA in TC (Figure 6).

Acetic, propionic, and butyric acids were found to be the main SCFAs produced during the fermentation process using an in vitro model of samples rich in phenolic compounds such as cranberry and grape seed extracts by the gut microbiota. In addition, in this type of assay, the content of SCFAs was higher in the DC than in the AC [38]. Considering in vivo assays, the group of rats fed with an onion supplemented diet produced significant higher concentrations of SCFAs than the control group fed with a traditional rat diet without onion [68]. Furthermore, in vitro gut fermentation studies carried out with quercetin, the main flavonol found in onions, resulted in a high accumulation of propionic acid; meanwhile, the fermentation of caffeic acid showed the increase of butyric acid respective to other SCFAs [24]. However, in the present study, the main SCFAs were acetic acid 
followed by propionic acid in AC and DC except in the TC where butyric acid was the main compound from day 6 to day 10 of the study.

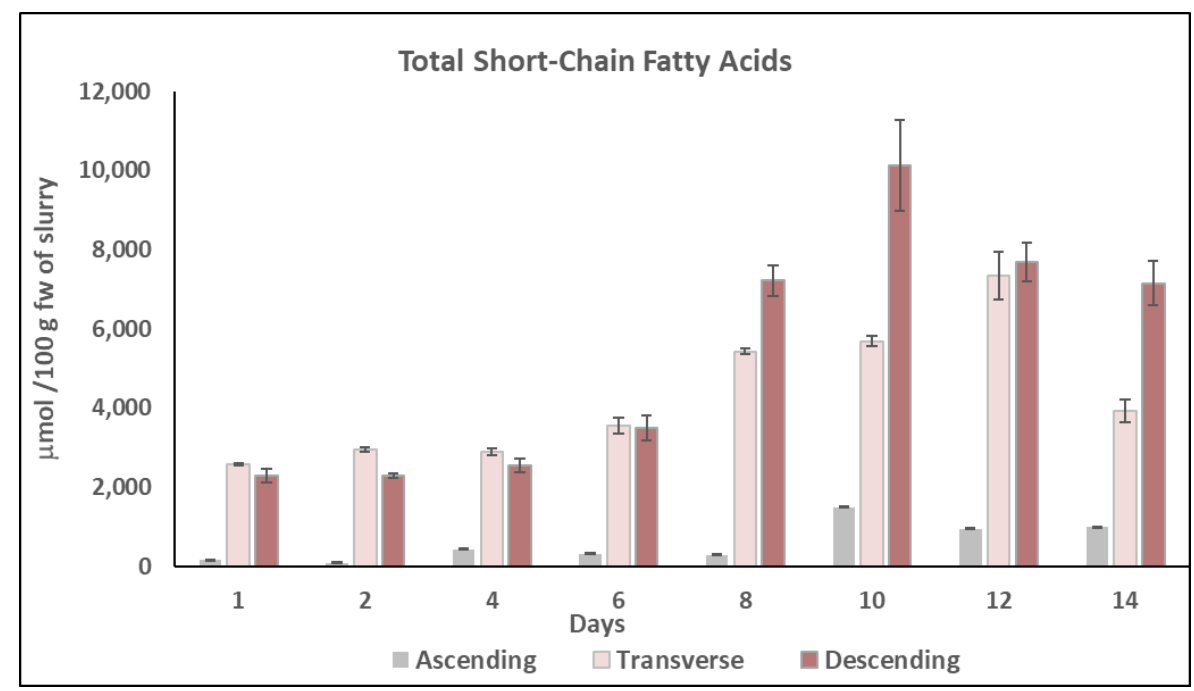

Figure 7. Total concentration ( $\mu \mathrm{mol} / 100 \mathrm{~g}$ fw of slurry) of short-chain fatty acids (SCFAs) in the ascending colon (AC), transverse colon (TC), and descending colon (DC) during the colonic fermentation of HPP-treated onion. Data are the mean values \pm standard deviation of three different determinations $(n=3)$.

The increase of SCFA concentration during chronic feeding with HPP-treated onion in a DGID-CF simulator indicates that this intake could improve the host health because SCFAs play an important role in the production of gut hormones, act in the brain to regulate food intake, exert protective effects against enteric pathogen colonization and infection, and play an important role in the prevention and treatment of metabolic diseases and the prevention of cardiovascular disease, among other functions [26]. Moreover, the increasing concentration of butyric acid in the TC due to the consumption of HPP-treated onion indicates an important protection against colon cancer [28].

As a consequence of the degradation of proteins and amino acids by gut microbiota, small amounts of fatty acids such as isoC4, C5, C6, and C7 were found mainly in the DC. In both the TC and the $\mathrm{DC}$, a peak level was observed at day 10 of the study, $\mathrm{C} 5$ being the main compound in the TC (181.07 $\pm 3.97 \mu \mathrm{mol} / 100 \mathrm{~g}$ fw of slurry), while in the DC, it was C6 (1014.06 $\pm 150 \mu \mathrm{mol} / 100 \mathrm{~g} \mathrm{fw}$ of slurry). Contrary to the present study results, other authors only observed an increment of isoC 4 in the AC during an in vitro gut fermentation of cranberry and grape seed polyphenols [38]. In addition, non-significant differences were found in the $\mathrm{C} 4, \mathrm{C} 5$, isoC5, C6, and $\mathrm{C} 7$ content in the cecum of Wistar rats fed with blackcurrant, blackberry, and raspberry extracts [69].

\section{Materials and Methods}

\subsection{Reagents}

Methanol LC/MS grade was acquired from J.T. Baker (Deventer, The Netherlands). The rest of the solvents employed were HPLC-grade from Lab-Scan (Dublin, Ireland). Commercial standards of C2:0, C3:0, C4:0, and C5:0 fatty acids were acquired from Applied Science Laboratories Inc. (State College, PA, USA). The rest of the commercial standards and the chemical products employed in the different analyses carried out were supplied by Sigma Aldrich (St. Louis, MO, USA).

\subsection{Raw Material}

Onions (Allium cepa L. var. cepa, 'Recas') from Carabaña (Madrid, Spain) were purchased from a local supermarket located in Madrid and stored at $4{ }^{\circ} \mathrm{C}$ until processed. 
External layers were removed, and bulbs were cut into $10 \mathrm{~mm}$ cubes, packaged $(200 \mathrm{~g})$ in low permeability plastic bags (BB4L, Cryovac, Barcelona, Spain), and sealed with light vacuum.

\subsection{High-Pressure Processing (HPP)}

The onion bags were treated at $400 \mathrm{MPa}$ for $5 \mathrm{~min}$ at $25^{\circ} \mathrm{C}$. These treatment conditions were selected due to the good results in terms of health-promoting characteristics demonstrated for this HPP-treated onion by in vitro and in vivo assays carried out with Wistar rats $[40,41,70,71]$. The hydrostatic pressure unit was formed by a vessel of $1925 \mathrm{~mL}$ capacity and it was able to work to a maximum pressure of $800 \mathrm{MPa}$ and a maximum temperature of $70{ }^{\circ} \mathrm{C}$ (High Pressure Iso-Lab System, Model FPG7100:9/2C, Stansted Fluid Power LTD., Essex, UK). Two bags of packaged onions were placed into the vessel unit filled with water as a pressure-transmitting medium. The compression and decompression rates were both $3 \mathrm{MPa} / \mathrm{s}$. Because of adiabatic compression, the maximum temperature in the vessel was $25^{\circ} \mathrm{C}$ at $400 \mathrm{MPa}$. Pressure, time, and temperature were controlled by a computer program, being constantly monitored and recorded during the process.

Onion treated by high-pressure processing (HPP-treated onion) was immediately frozen with liquid nitrogen and stored at $-80{ }^{\circ} \mathrm{C}$ until lyophilization $\left(100 \mathrm{mTorr},-90{ }^{\circ} \mathrm{C}\right)$ using a lyophilizator model Lyoalfa (Telstar, Barcelona, Spain). Lyophilized samples were pulverized in an ultracentrifugal grinder ZM 200 (Retsch GmbH, Haan, Germany) to obtain a fine powder (particle size $\leq 0.5 \mathrm{~mm}$ ), and maintained at $-20{ }^{\circ} \mathrm{C}$ until analyzed.

\subsection{Characterization of HPP-Treated Onion Powder}

The effect of HPP at $400 \mathrm{MPa} / 25^{\circ} \mathrm{C} / 5$ min on physicochemical and chemical characteristics of the 'Recas' onion has been previously studied [46,70,71]. The physicochemical and chemical characteristics of HPP-treated onion powder are shown in Table 1. Titratable acidity, $\mathrm{pH}$, total vitamin $\mathrm{C}$, and ascorbic acid were determined according to [45]. Sugars and organic acids content were analyzed according to Colina-Coca et al. [71]. Soluble proteins were analyzed according to the BioRad assay based on Bradford [72]. Soluble, insoluble, and total fiber (AOAC 991.43, 2012) were also determined.

\subsection{Dynamic In Vitro Gastrointestinal and Colonic Fermentation (DGID-CF) Model}

A dynamic in vitro model system able to simulate the complete digestion process, i.e., gastrointestinal digestion and colonic fermentation (DGID-CF) was developed by AINIA Technologic Center (Valencia, Spain) based on different authors $[39,49,73,74]$. This system consists of five vessels to simulate the physiological conditions taking place during digestion in the stomach, small intestine, and ascending (AC), transverse (TC) and descending colon (DC). All the vessels were protected from light and connected by peristaltic pumps working semi-continuously in the stomach and small intestine, and continuously in the three colon regions (Figure 8). The five vessels were under agitation (150 rpm) and the whole process conditions, $\mathrm{pH}$ values, residence times, temperature $\left(37^{\circ} \mathrm{C}\right)$ and volume capacities, were computer-controlled (Figure 8). Anaerobiosis in the five vessels was maintained by flushing gaseous $\mathrm{N}_{2}$ for 15 min twice a day.

The gastrointestinal digestion (stomach and small intestine) conditions were similar to Minekus et al. (2014) [75]. This system was previously employed to study the bioaccessibility of flavonols in HPP-treated onion by Fernández-Jalao et al. (2017) [46]. Briefly, the gastric digestion step was simulated by the addition of $60 \mathrm{~mL}$ of a $0.03 \%(w / v)$ pepsin solution (2100 units $/ \mathrm{mg}$ ) made with simulated gastric electrolyte solution to the stomach vessel. In contrast, the small intestine digestion was simulated by the addition of $240 \mathrm{~mL}$ of a solution containing pancreatin $(0.9 \mathrm{~g} / \mathrm{L})$ and fresh bile $(6 \mathrm{~g} / \mathrm{L})$ made with a simulated intestinal electrolyte solution in distilled water. The $\mathrm{pH}$ in the stomach $(\mathrm{pH} 2)$ and small intestine ( $\mathrm{pH}$ 5-6) was adjusted with hydrochloric acid $1 \mathrm{M}$ or sodium bicarbonate, respectively. Once the gastric digestion $(2 \mathrm{~h})$ and small intestine digestion was finished $(6 \mathrm{~h})$, the intestinal digestion was incorporated three times a day to the ascending colon reactor. 


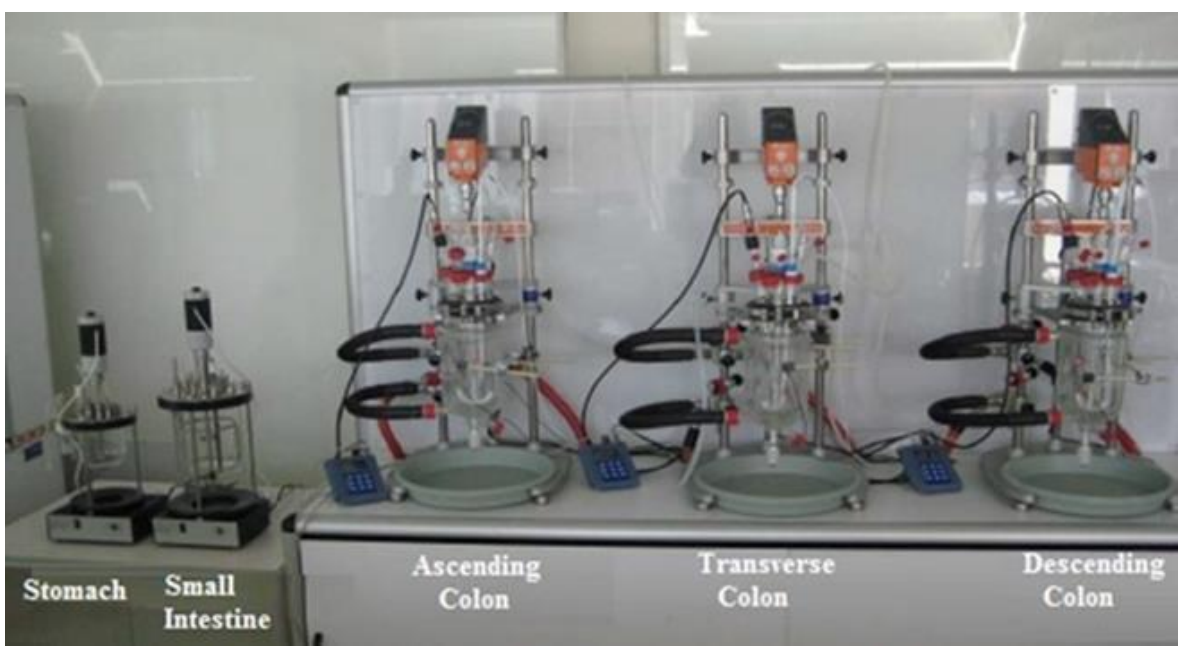

Figure 8. Dynamic in vitro model system to simulate the whole digestion process, gastrointestinal digestion, and colonic fermentation (DGID-CF) developed by AINIA (Valencia, Spain).

A pool of feces from five healthy volunteers with a varied diet, no history of gastrointestinal disorders, no smokers, no food allergies, not taking any vitamins or supplements, and having taken no antibiotics in the three months prior to start the study was used. Samples were collected on site on the day of the experiment and were used immediately. All volunteers gave their informed consent for the use of their feces in the study. The study was conducted in accordance with the Declaration of Helsinki, and the protocol was approved by the Ethics Committee of the AINIA Technology Centre (AINIA procedure no. 1180/15).

Prior to the inoculation with $20 \mathrm{~mL}$ of human fecal slurry $(20 \%, w / v)$ obtained by mixing the fresh feces with sodium phosphate $(\mathrm{pH} 7)$, the colon vessels were filled and pre-conditioned with a nutritive medium in a volume of $1000 \mathrm{~mL}$ in the AC, $1600 \mathrm{~mL}$ in the TC, and $1200 \mathrm{~mL}$ in the DC [76,77]. The composition for $1 \mathrm{~L}$ of the nutritive medium was $1 \mathrm{~g}$ of arabinogalactan, $0.2 \mathrm{~g}$ of pectin from apple, $1 \mathrm{~g}$ of xylan, $3 \mathrm{~g}$ of potato starch, 0.4 of glucose, $3 \mathrm{~g}$ of yeast extract, $1 \mathrm{~g}$ of peptone, $4 \mathrm{~g}$ of mucin, $0.5 \mathrm{~g}$ of L-cysteine, $1.5 \mathrm{~g}$ of $\mathrm{NaHCO}_{3}, 0.69$ of $\mathrm{MgSO}_{4} \cdot \mathrm{H}_{2} \mathrm{O}, 0.5 \mathrm{~g}$ of $\mathrm{KH}_{2} \mathrm{PO}_{4}, 0.5 \mathrm{~g}$ of $\mathrm{K}_{2} \mathrm{HPO}_{4}, 0.08 \mathrm{~g} \mathrm{CaCl}_{2}, 0.005 \mathrm{~g}$ of $\mathrm{FeSO}_{4} \cdot 7 \mathrm{H}_{2} \mathrm{O}, 0.002 \mathrm{~g}$ of $\mathrm{MnSO}_{4} \cdot \mathrm{H}_{2} \mathrm{O}, 0.0006 \mathrm{~g}$ of $\mathrm{ZnSO}_{4} \cdot 7 \mathrm{H}_{2} \mathrm{O}, 0.0001 \mathrm{~g}$ of $\mathrm{CoSO}_{4} \cdot 6 \mathrm{H}_{2} \mathrm{O}$, $10 \mu \mathrm{L}$ of vitamin $\mathrm{K} 1,1 \mathrm{~mL}$ of Tween 80 and $4 \mathrm{~mL}$ of resazurin solution $(0.025 \%, w / v)$ as an anaerobic indicator, and distilled water. The medium was sterilized at $121{ }^{\circ} \mathrm{C}$ for $15 \mathrm{~min}$ and oxygen was eliminated by flushing nitrogen before being placed in the three colon reactors. The $\mathrm{pH}$ of the medium of each reactor was adjusted and controlled at 5.5-6 for AC, 6-6.4 for TC and 6.4-6.8 for DC and maintained under anaerobic conditions by continuously flushing $\mathrm{N}_{2}$.

The experimental procedure consisted of two phases. An initial stabilization period (basal) of 12 days allowed the intestinal microbiota to adapt to the nutritional and physicochemical conditions present in the three colon vessels (AC, TC, and DC). During this period, $200 \mathrm{~mL}$ of nutritive medium was added three times a day to the stomach reactor to feed the system (Figure 9). The second phase corresponded to the intake period, which consisted of adding $27 \mathrm{~g}$ of HPP-treated onion to the stomach vessel once a day for 14 days, together with $200 \mathrm{~mL}$ of nutritive medium simulating a chronic intake. In addition, the system was fed twice a day only with $200 \mathrm{~mL}$ of nutritive medium. The volume and transit time of each compartment of the DGID-CF simulating the in vivo residence time were: $260 \mathrm{~mL}$ and $2 \mathrm{~h}$ in the stomach, $460 \mathrm{~mL}$ and $3 \mathrm{~h}$ in the small intestine, $1000 \mathrm{~mL}$ and $20 \mathrm{~h}$ in the AC, $1600 \mathrm{~mL}$ and $32 \mathrm{~h}$ in the TC, and $1200 \mathrm{~mL}$ and $24 \mathrm{~h}$ in the DC (Figure 9). 


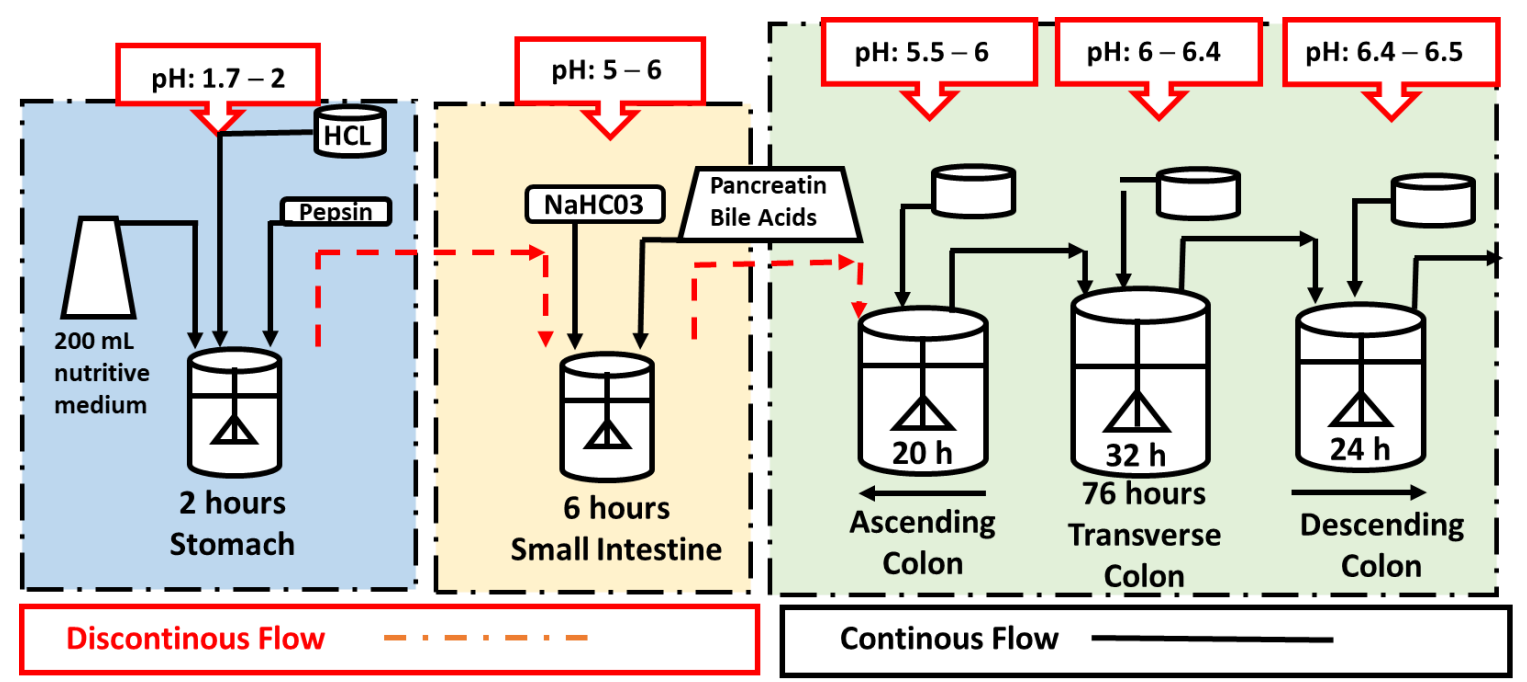

Figure 9. Experimental conditions of the in vitro gastrointestinal digestion and colonic fermentation in a dynamic model digestor (AINIA, Valencia, Spain).

During the experimental set up, samples of $50 \mathrm{~g}$ from the three colon reactors (AC, $\mathrm{TC}$, and DC) were collected once a day during the 14 days of experiment to study the metabolic activity of intestinal microbiota (phenolic metabolites and short-chain fatty acid analysis). All these samples were quicky aliquoted and stored at $-20{ }^{\circ} \mathrm{C}$ in darkness until they were transported from AINIA to ICTAN under controlled freezing conditions. On arrival, they were immediately stored at $-80^{\circ} \mathrm{C}$ for one week and then subjected to lyophilization (Lyophilizator model Lyoalfa, Telstar S.A, Barcelona, Spain). The lyophilized samples were homogenized manually with a domestic grinder and stored at $-20^{\circ} \mathrm{C}$ until analysis. For the evaluation of colonic microbiota modulation, samples of $5 \mathrm{~g}$ from the three colon reactors (AC, TC, and DC) were collected in aseptic conditions at regular time points during the stabilization $(0,6,8,10$, and 12 days) and intake period $(1,3,5,7,9$, and 13 days), immediately stored at $4{ }^{\circ} \mathrm{C}$, and analyzed within two hours at the AINIA microbiology laboratory. Two different gastrointestinal digestion-colon fermentation digestions were carried out.

\subsection{Analysis of Phenolic Compounds and Metabolites by HPLC-DAD-ESI-QTOF-MS/MS} 3.6.1. Phenolic Compounds in the HPP-Treated Onion Powder

The extraction of phenolic compounds of the undigested HPP-treated onion powder was carried out according to a procedure previously described [46]. Briefly, $0.5 \mathrm{~g}$ of HPPtreated onion was mixed with $12.5 \mathrm{~mL}$ of extraction solvent (methanol/water, 80:20, $v / v$ ) and homogenizer using an ultrahomogenizer at $8000 \mathrm{rpm}$ for $4.5 \mathrm{~min}$ (model ES-270, Omni International Inc., Gainesville, VA, USA). The mixtures were centrifuged $(8000 \times g$, $4{ }^{\circ} \mathrm{C}, 15 \mathrm{~min}$ ) using a refrigerated centrifuge (Thermo Scientific Sorvall, mod. Evolution RC, Thermo Fischer Scientific Inc., Waltham, MA, USA). The pellet was re-extracted with $12.5 \mathrm{~mL}$ of extraction solvent and centrifuged again. Finally, the two supernatants were combined, evaporated at $40^{\circ} \mathrm{C}$ using a vacuum evaporator, reconstituted with $10 \mathrm{~mL}$ of methanol, and stored at $-20^{\circ} \mathrm{C}$ until analysis by HPLC-DAD- ESI-QTOF-MS/MS. Analysis was performed in triplicate $(n=3)$.

\subsubsection{Phenolic Compounds and Metabolites in the Colon Fermentation Products}

For the extraction of phenolic compounds and metabolites from the colonic fermentation products (ascending, transverse, and descending colon), $25 \mathrm{mg}$ of lyophilized samples was mixed with $1.5 \mathrm{~mL}$ of methanol/acidified water $(0.1 \%$ formic acid) $(80: 20 \mathrm{v} / \mathrm{v})$. The mixtures were vortexed for $1 \mathrm{~min}$, sonicated for $5 \mathrm{~min}$, and centrifuged at $11,400 \times \mathrm{g}$ (Thermo Scientific Sorvall, mod. Evolution RC, Thermo Fisher Scientific Inc., Waltham, 
MA, USA) for $15 \mathrm{~min}$ at $4{ }^{\circ} \mathrm{C}$. The supernatants were separated and centrifuged twice more in the same conditions. The final supernatant $(1 \mathrm{~mL})$ was diluted with $2 \mathrm{~mL}$ of ultrapure water (or $2 \mathrm{~mL}$ of methanol/water, 80:20 $(v / v)$ for detection and quantification of quercetin aglycone). The extraction was done in triplicate. One quality control (QC) (mix of extracts of all samples) and one pool sample by zone (mix of extracts of all samples from each colon region: ascending, transverse, and descending) were also prepared. The extracts were filtered through a $0.22 \mu \mathrm{m}$ filter before their analysis by HPLC-DAD-ESI-QTOF-MS/MS. Analysis was performed in triplicate $(n=3)$.

3.6.3. HPLC-DAD-ESI-QTOF-MS/MS Analysis of Phenolic Compounds and Metabolites. Metabolomic Analysis by a Targeted Approach

The separation, identification, and quantitation of phenolic compounds and their metabolites was achieved by high performance liquid chromatography-mass spectrometry system with a diode array detector (DAD) and coupled to an Agilent 6530 Accurate-Mass Quadrupole Time-of-Flight (Q-TOF) MS system equipped with an Agilent Jet Stream dual electrospray ionization (ESI) source (HPLC-DAD-ESI-QTOF-MS/MS)(Agilent Technologies Inc., Santa Clara, CA, USA). The HPLC system was equipped with a quaternary pump (G1311A) with an integrated degasser (G1322A), thermostated automatic injector (G1367B), thermostated column module (G1316A), and a diode detector array (DAD) (G1315B) (Agilent Technologies, Waldbronn, Germany). Separation was carried out on a $2.0 \times 50 \mathrm{~mm}$ id., $3.0 \mu \mathrm{m}$ particle size, Luna C18 column (Phenomenex, Torrance, CA, USA). The mobile phase consisted of a linear gradient of $0.1 \%$ formic acid in Milli-Q-water (A) and $0.1 \%$ formic acid in acetonitrile (B) as follows: $0 \mathrm{~min}, 95 \% \mathrm{~A} ; 15 \mathrm{~min}, 80 \% \mathrm{~A} ; 25 \mathrm{~min}, 50 \% \mathrm{~A}$; $30 \mathrm{~min}, 20 \% \mathrm{~A} ; 40 \mathrm{~min}, 95 \% \mathrm{~A}$. The flow rate was fixed at $0.4 \mathrm{~mL} / \mathrm{min}$ and the injection volume was $10 \mu \mathrm{L}$. Runs were monitored at $360 \mathrm{~nm}, 320 \mathrm{~nm}$, and $280 \mathrm{~nm}$.

To identify the phenolic compounds precursors and their possible metabolites, total ion spectra were collected in the range $m / z 100-1000$ in negative mode. Nitrogen was used as a drying, collision, and nebulizing gas. The drying gas temperature and flow rate were $225^{\circ} \mathrm{C}$ and $10 \mathrm{~L} / \mathrm{min}$, respectively. The sheath gas temperature and flow rate were $300{ }^{\circ} \mathrm{C}$ and $10 \mathrm{~L} / \mathrm{min}$. The nebulizer gas pressure, skimmer voltage, octopole RF, and fragmentor voltage were $45 \mathrm{psi}, 65 \mathrm{~V}, 750 \mathrm{~V}$, and $125 \mathrm{~V}$, respectively. The capillary voltage was set at $3 \mathrm{kV}$. The MS/MS collision energy was set at $15 \mathrm{eV}$.

Data were acquired and analyzed using a Masshunter Qualitative Analysis B.07.00 software and Masshunter Profinder B.08.00 software (Agilent Technologies Inc., Santa Clara, CA, USA), respectively. The identification was possible by comparison with the mass spectral data generated by external standards, the data from databases (MassBank, Pubchem, Phenol explorer, MoNa database), and a personal accurate mass database built using the information about mass data of the main phenolic compounds present in onion and their possible metabolites obtained from the literature. The raw data collected by LC-MS was cleaned of background noise and unrelated ions by the molecular feature extraction (MFE) algorithm using the Mass Hunter Qualitative Analysis Software B.06.00 (Agilent Technologies, Inc, Santa Clara, CA, USA). The MFE then created a list of the ion characteristics for the phenolic compounds and their corresponding metabolite profiles; each compound was described by mass, retention time, and abundance. Features postacquisition processing was performed in Agilent Profinder B.08.00 (Agilent Technologies Inc., Santa Clara, CA, USA). Mass and retention time alignment followed by a filter-byfrequency post-processing was done to retain only those features that were present in $>70 \%$ of samples within at least one treatment. Relative standard deviation (\%RSD) of the concentration of the compounds in the QCs (quality control) samples was calculated, and only compounds below the limit (30\%) were considered for the data treatment.

Quantification of phenolic compounds precursors and metabolites was performed in the QTOF in MS1 mode using external calibration curves that were each systematically injected 10 runs of the injection sequence. Standard calibration curves of five points were made for each compound commercially available in the range of 5 to $0.005 \mu \mathrm{g} / \mathrm{mL}$. When no commercial standard was available, the compounds or the metabolites were 
quantified using structurally related commercial standards. The quality control samples were prepared mixing $10 \mu \mathrm{L}$ of each sample extract. Analysis was performed in triplicate $(n=3)$.

\subsection{Microbial Analysis}

Although there are accurate molecular methods such as quantitative PCR and fluorescence in situ hybridization (FISH) with ribosomal RNA-targeted oligonucleotide probes, in the present study bacterial count methods were employed. Thus, samples ( $5 \mathrm{~g}$ fw of slurry) from the three colon vessels $(\mathrm{AC}, \mathrm{TC}$, and $\mathrm{DC}$ ) during the stabilization (at $0,6,8$, and 12 days) and intake period (at $0,2,5,7,9$, and 13 days) were aseptically transferred to tubes containing Anaerobe Basal Broth (Oxoid, Thermo Scientific, Basingstoke, UK) transported immediately to the microbiology laboratory of AINIA (Valencia, Spain), and analyzed within two hours [78]. The isolation and enumeration of specific groups of bacteria from the fermentation products were done using selective and differential growth media and suitable incubation conditions [79]: VRBD Agar (Merck-Millipore, Burlington, MA, USA) for Enterobacteriaceae; VRBL Agar (Merck-Millipore) for total coliforms; TSC Agar (Oxoid) for Clostridium spp.; Tos-propionate Agar (Merck-Millipore) for Bififobacterium spp.; Schaedler Anaerobe Agar (Oxoid) for total anaerobes; and MRS Agar (Oxoid) for Lactobacillus spp. All plates were incubated at $37^{\circ} \mathrm{C}$ in anaerobic conditions for $24 \mathrm{~h}$ (Enterobacteriaceae, Clostridium spp., and total coliforms), $48 \mathrm{~h}$ (Bififobacterium spp. and Lactobacillus spp.), and $72 \mathrm{~h}$ (total anaerobes). The identification of Lactobacillus microorganisms from MRS-agar plates were carried out by MALDI-TOF mass spectrometry [80]. Anaerobic bacteria and Enterobacteriaceae were analyzed as indicators of total colonic microbiota, total coliforms, and Clostridium spp. as a part of regular microbiota composition. Although they are associated with potential harmful effects, Bifidobacterium spp. and Lactobacillus spp. were associated with the beneficial microbiota of the colon. Analysis was performed in triplicate $(n=3)$.

\subsection{Analysis of Short-Chain Fatty Acids (SCFAs)}

The SCFAs were derivatized using the methodology previously described by CastroGomez et al. [81]. Briefly, $100 \mathrm{mg}$ of lyophilized colonic fermentation products dissolved in $400 \mathrm{~L}$ of Milli-Q water was mixed with $2.50 \mathrm{~mL}$ of sodium methoxide $0.5 \mathrm{M}$ solution in methanol and $50 \mu \mathrm{L}$ of nonanoic acid (C9:0) and tritridecanoine (C13:0-TAG) solution as internal standards, $1 \mathrm{mg} / \mathrm{mL}$. The samples were heated at $80^{\circ} \mathrm{C}, 10 \mathrm{~min}$, and $1300 \mathrm{rpm}$ using an incubator with shaker function (TR100-G; JP Selecta, Barcelona, Spain). The samples were cooled in ice for $5 \mathrm{~min}$, and then $1.83 \mathrm{~mL}$ of dimethylsulfoxide (DMSO) and $3 \mathrm{~mL}$ of $\mathrm{H}_{2} \mathrm{SO}_{4}(1 \mathrm{M})$ were added. The samples were incubated again $\left(60^{\circ} \mathrm{C}, 30 \mathrm{~min}\right.$, and $1300 \mathrm{rpm}$ ) and cooled later. Then, $1 \mathrm{~mL}$ of hexane and $7.5 \mathrm{~mL}$ of $6 \% \mathrm{Na}_{2} \mathrm{CO}_{3}$ solution were incorporated into samples and the mixtures were centrifuged at $0{ }^{\circ} \mathrm{C}, 3500 \mathrm{rpm}$, and $10 \mathrm{~min}$, using a refrigerated centrifuge (Hettich Universal centrifuge 320R, Tuttlingen, Germany). The upper layer of hexane was transferred to a vial for GC-MS analysis. The same derivatization method was applied to the reference mix $(1 \mathrm{mg} / \mathrm{mL})$ prepared from commercial standards of fatty acids (C4:0, C5:0, C7:0, C8:0, and C9:0).

The analysis of fatty acid methyl esters (FAMEs) obtained was performed in an Agilent 6890 Series gas chromatograph (Agilent Technologies, Heilbronn, Germany) coupled to an Agilent 5973 Series mass spectrometer (Agilent Technologies, Heilbronn, Germany). Chromatographic separation was performed in a CPSil-88 capillary column $(100 \mathrm{~m} \times$ $0.25 \mathrm{~mm} \times 0.2 \mu \mathrm{m})$ (Chrompack, Middelburg, The Netherlands). Helium (purity 99.999\%) was used as a carrier gas with a column inlet pressure of $30 \mathrm{psi}$. The injection volume was $1 \mu \mathrm{L}$ and the split ratio was 1:25. The temperature program was as follows: $1 \mathrm{~min}$ at $70{ }^{\circ} \mathrm{C}$, first ramp $7{ }^{\circ} \mathrm{C} / \mathrm{min}$ to $170{ }^{\circ} \mathrm{C}$, and secondary ramp at $10^{\circ} \mathrm{C} / \mathrm{min}$ to $230{ }^{\circ} \mathrm{C}$. The total analysis run was $76.29 \mathrm{~min}$. MS detector conditions were as follows: transfer line temperature $250{ }^{\circ} \mathrm{C}$, source temperature $230^{\circ} \mathrm{C}$, and quad temperature $150{ }^{\circ} \mathrm{C}$. The mass spectrometer was operated under electron impact ionization at $70 \mathrm{eV}$; it was used 
in total ion current (TIC) mode and scanned the mass range from 40 to $500 \mathrm{~m} / \mathrm{z}$. For SCFA identification of colonic fermentation samples, the retention time and mass spectra were compared with those obtained in a mix of commercial standards and data from the National Institute of Standards and Technology library (NIST, 2.1.0 version; Gaithersburg, MD, USA). Quantitation was achieved using response factors calculated from the internal standards. Analysis was performed in triplicate $(n=3)$.

\subsection{Statistical Analysis}

The results shown represent mean values \pm standard deviation (SD). These results were calculated from the mean value obtained in at least three separate experiments $(n=3)$. To study statistically significant differences $(p \leq 0.05)$ in flavonols and their metabolite content, short-chain fatty acids production, and microbiota composition in the three colon regions at different fermentation days, one-way analysis of variance (ANOVA) was applied followed by Tukey's b post hoc test. Levenne's test was applied to verify the homogeneity of the variances. All analyses were performed using the IBM SPSS Statistics 23 Core System (SPSS Inc., an IBM Company, Armonk, NY, USA).

Multivariate analysis based on principal component analysis (PCA) was applied to assess the quality of data obtained by HPLC-DAD-ESI-QTOF-MS/MS using the MetaboAnalyst 4.0 software (MetaboAnalystR package) (XiaLab, MacGill University, Montreal, QC, Canada) [82]. Pareto was used as a scaling method and a logarithmic transformation was performed in order to approximate a normal distribution. In order to evaluate the quality of analytical data and to remove possible outliers, a PCA was performed from fecal samples and quality controls (QCs). The robustness of analytical procedure was proven by the clustering of the QC samples (data not shown), which reflects the system's stability and performance and the reproducibility of the sample treatment procedures.

\section{Conclusions}

To our knowledge, there are no published studies about the effect of a natural food source of flavonols, such as an onion product treated by high-pressure processing (HPPtreated onion) and subsequently lyophilized, on human gut microbiota metabolism by the simulation of chronic feeding with $27 \mathrm{~g} /$ day for 14 days using a dynamic in vitro gastrointestinal digestion and colon fermentation (DGID-CF) simulator. This simulator was composed of different reactors that mimic the conditions of the stomach, small intestine, and the three colon regions, ascending (AC), transverse (TC), and descending colon (DC).

Chronic feeding with $27 \mathrm{~g} /$ day of HPP-treated onion produced a significant accumulation of flavonols, mainly Q-3,4'-diglucoside, Q-4'-glucoside, Iso-4'-glucoside, and quercetin aglycone in the $\mathrm{AC}$, that were metabolized by colonic microbiota, leading to a different flavonol metabolite profile depending on the colon region (AC, TC, DC). In the AC, the total metabolite content was 3.5 and 4 times lower than in the TC and DC, respectively. During the intake period, total metabolite content progressively increased, mainly in TC and DC, reaching a peak level at day 12 that was 2.5 times higher than at the beginning of the intake period. The main flavonol metabolites found in TC and DC have been related with important health-promoting properties and in descending order of concentration were 3-hydroxyphenylacetic acid, 4-hydroxyphenylacetic acid, 2-hydroxyphenylacetic acid, and 3-(3-hydroxyphenyl)-propionic and 3-(4-hydroxyphenyl)-propionic acids. Furthermore, the beneficial effect of chronic feeding with the HPP-treated onion was the increased level of Bifidobacterium spp. and Lactobacillus spp, considered part of beneficial colon bacteria, and the decreased Enterobacteria, total coliforms, and Clostridium spp. concentration as potential harmful bacteria. The beneficial effects on the composition of the microbiota produced by the HPP-treated onion can also be reflected in the increased production of SCFAs, mainly acetic acid followed by propionic acid in the AC and DC and butyric acid in the TC.

Data provided in the present study showed that HPP-treated onion is a good dietary source of flavonols that, in contact with human gut microbiota, resulted in phenolic 
metabolites and short-chain fatty acids production as well as the modulation of certain bacterial groups, changes that have been associated with health beneficial effects. However, more studies have to be done to know if the untreated onion would produce the same results as the HPP-treated onion.

Author Contributions: Conceptualization, B.D.A. and C.S.-M.; methodology, B.D.A., C.S.-M. and J.F.; software, I.F.-J. and C.B.; formal analysis, I.F.-J. and M.V.C.; visualization, I.F.-J.; writing-original draft preparation, I.F.-J. and B.D.A.; writing—review and editing, I.F.-J., B.D.A., C.S.-M. and J.F.; supervision, B.D.A. and C.S.-M.; project administration, B.D.A.; funding acquisition, B.D.A. and C.S.-M. All authors have read and agreed to the published version of the manuscript.

Funding: This study has been funded by the Spanish Ministry of Economy and Competitiveness (MINECO) by the projects AGL2013-46326-R, AGL2016-76817-R and PID2019-107980RB-100.

Institutional Review Board Statement: The study was conducted in accordance with the Declaration of Helsinki, and the protocol was approved by the Ethics Committee of the AINIA Technology Centre (AINIA procedure no. 1180/15).

Informed Consent Statement: Informed consent was obtained from all subjects involved in the study.

Data Availability Statement: Not applicable.

Acknowledgments: We are grateful to the Analysis Service Unit facilities of ICTAN for the analysis of Chromatography and Mass Spectrometry. We would also like to thank Lucia Gimenez for her excellent laboratory technical assistance.

Conflicts of Interest: The authors declare no conflict of interest.

\section{References}

1. FAOSTAT. Food and Agriculture Organization of the United Nations. Crops. Onions, Dry. Available online: http:/ /www.fao. org/faostat/en/\#data/QC (accessed on 21 April 2020).

2. Teshika, J.D.; Zakariyyah, A.M.; Zaynab, T.; Zengin, G.; Rengasamy, K.R.R.; Pandian, S.K.; Fawzi, M.M. Traditional and modern uses of onion bulb (Allium cepa L.): A systematic review. Crit. Rev. Food Sci. Nutr. 2019, 59, S39-S70. [CrossRef]

3. Griffiths, G.; Trueman, L.; Crowther, T.; Thomas, B.; Smith, B. Onions-A global benefit to health. Phytother. Res. 2002, 16, 603-615. [CrossRef]

4. Briones-Labarca, V.; Venegas-Cubillos, G.; Ortiz-Portilla, S.; Chacana-Ojeda, M.; Maureira, H. Effects of high hydrostatic pressure (HHP) on bioaccessibility, as well as antioxidant activity, mineral and starch contents in Granny Smith apple. Food Chem. 2011, 128, 520-529. [CrossRef]

5. Serra, A.; Macia, A.; Romero, M.P.; Reguant, J.; Ortega, N.; Motilva, M.J. Metabolic pathways of the colonic metabolism of flavonoids (flavonols, flavones and flavanones) and phenolic acids. Food Chem. 2012, 130, 383-393. [CrossRef]

6. Slimestad, R.; Fossen, T.; Vagen, I.M. Onions: A source of unique dietary flavonoids. J. Agric. Food Chem. 2007, 55, 10067-10080. [CrossRef]

7. Wang, W.Y.; Sun, C.X.; Mao, L.K.; Ma, P.H.; Liu, F.G.; Yang, J.; Gao, Y.X. The biological activities, chemical stability, metabolism and delivery systems of quercetin: A review. Trends Food Sci. Technol. 2016, 56, 21-38. [CrossRef]

8. Patel, R.V.; Mistry, B.M.; Shinde, S.K.; Syed, R.; Singh, V.; Shin, H.S. Therapeutic potential of quercetin as a cardiovascular agent. Eur. J. Med. Chem. 2018, 155, 889-904. [CrossRef] [PubMed]

9. Perez, A.; Gonzalez-Manzano, S.; Jimenez, R.; Perez-Abud, R.; Haro, J.M.; Osuna, A.; Santos-Buelga, C.; Duarte, J.; PerezVizcaino, F. The flavonoid quercetin induces acute vasodilator effects in healthy volunteers: Correlation with beta-glucuronidase activity. Pharmacol. Res. 2014, 89, 11-18. [CrossRef] [PubMed]

10. Jakobek, L. Interactions of polyphenols with carbohydrates, lipids and proteins. Food Chem. 2015, 175, 556-567. [CrossRef]

11. Ribas-Agusti, A.; Martin-Belloso, O.; Soliva-Fortuny, R.; Elez-Martinez, P. Food processing strategies to enhance phenolic compounds bioaccessibility and bioavailability in plant-based foods. Crit. Rev. Food Sci. Nutr. 2018, 58, 2531-2548. [CrossRef] [PubMed]

12. Williamson, G.; Manach, C. Bioavailability and bioefficacy of polyphenols in humans. II. Review of 93 intervention studies. Am. J. Clin. Nutr. 2005, 81, 243S-255S. [CrossRef]

13. Ozdal, T.; Sela, D.A.; Xiao, J.B.; Boyacioglu, D.; Chen, F.; Capanoglu, E. The Reciprocal Interactions between Polyphenols and Gut Microbiota and Effects on Bioaccessibility. Nutrients 2016, 8, 78. [CrossRef]

14. Rinninella, E.; Raoul, P.; Cintoni, M.; Franceschi, F.; Miggiano, G.A.D.; Gasbarrini, A.; Mele, M.C. What is the healthy gut microbiota composition? A changing ecosystem across age, environment, diet, and diseases. Microorganisms 2019, 7, 14. [CrossRef] 
15. Ulbrich, K.; Reichardt, N.; Braune, A.; Kroh, L.W.; Blaut, M.; Rohn, S. The microbial degradation of onion flavonol glucosides and their roasting products by the human gut bacteria Eubacterium ramulus and Flavonifractor plautii. Food Res. Int. 2015, 67, 349-355. [CrossRef]

16. Aura, A.M. Microbial metabolism of dietary phenolic compounds in the colon. Phytochem. Rev. 2008, 7, 407-429. [CrossRef]

17. Mosele, J.I.; Macia, A.; Motilva, M.J. Metabolic and Microbial Modulation of the Large Intestine Ecosystem by Non-Absorbed Diet Phenolic Compounds: A Review. Molecules 2015, 20, 17429-17468. [CrossRef]

18. Selma, M.V.; Espín, J.C.; Tomas-Barberán, F.A. Interaction between phenolics and gut microbiota: Role in human health. J. Agric. Food Chem. 2009, 57, 6485-6501. [CrossRef] [PubMed]

19. Dueñas, M.; Surco-Laos, F.; Gonzalez-Manzano, S.; Gonzalez-Paramas, A.M.; Santos-Buelga, C. Antioxidant properties of major metabolites of quercetin. Eur. Food Res. Technol. 2011, 232, 103-111. [CrossRef]

20. Larrosa, M.; Luceri, C.; Vivoli, E.; Pagliuca, C.; Lodovici, M.; Moneti, G.; Dolara, P. Polyphenol metabolites from colonic microbiota exert anti-inflammatory activity on different inflammation models. Mol. Nutr. Food Res. 2009, 53, 1044-1054. [CrossRef] [PubMed]

21. Williamson, G.; Clifford, M.N. Colonic metabolites of berry polyphenols: The missing link to biological activity? Br. J. Nutr. 2010, 104, S48-S66. [CrossRef]

22. Krzysztoforska, K.; Mirowska-Guzel, D.; Widy-Tyszkiewicz, E. Pharmacological effects of protocatechuic acid and its therapeutic potential in neurodegenerative diseases: Review on the basis of in vitro and in vivo studies in rodents and humans. Nutr. Neurosci. 2019, 22, 72-82. [CrossRef] [PubMed]

23. Koutsos, A.; Lima, M.; Conterno, L.; Gasperotti, M.; Bianchi, M.; Fava, F.; Vrhovsek, U.; Lovegrove, J.A.; Tuohy, K.M. Effects of commercial apple varieties on human gut microbiota composition and metabolic output using an in vitro colonic model. Nutrients 2017, 9, 533. [CrossRef] [PubMed]

24. Parkar, S.G.; Trower, T.M.; Stevenson, D.E. Fecal microbial metabolism of polyphenols and its effects on human gut microbiota. Anaerobe 2013, 23, 12-19. [CrossRef] [PubMed]

25. Schloissnig, S.; Arumugam, M.; Sunagawa, S.; Mitreva, M.; Tap, J.; Zhu, A.; Waller, A.; Mende, D.R.; Kultima, J.R.; Martin, J.; et al. Genomic variation landscape of the human gut microbiome. Nature 2013, 493, 45-50. [CrossRef]

26. Cani, P.D.; Van Hul, M.; Lefort, C.; Depommier, C.; Rastelli, M.; Everard, A. Microbial regulation of organismal energy homeostasis. Nat. Metab. 2019, 1, 34-46. [CrossRef]

27. Lin, H.V.; Frassetto, A.; Kowalik, E.J.; Nawrocki, A.R.; Lu, M.F.M.; Kosinski, J.R.; Hubert, J.A.; Szeto, D.; Yao, X.R.; Forrest, G.; et al. Butyrate and propionate protect against diet-induced obesity and regulate gut hormones via free fatty acid receptor 3-independent mechanisms. PLoS ONE 2012, 7, 9. [CrossRef]

28. Waldecker, M.; Kautenburger, T.; Daumann, H.; Busch, C.; Schrenk, D. Inhibition of histone-deacetylase activity by short-chain fatty acids and some polyphenol metabolites formed in the colon. J. Nutr. Biochem. 2008, 19, 587-593. [CrossRef] [PubMed]

29. Perry, R.J.; Peng, L.; Barry, N.A.; Cline, G.W.; Zhang, D.Y.; Cardone, R.L.; Petersen, K.F.; Kibbey, R.G.; Goodman, A.L.; Shulman, G.I. Acetate mediates a microbiome-brain-beta-cell axis to promote metabolic syndrome. Nature 2016, 534, 213-217. [CrossRef] [PubMed]

30. Tirosh, A.; Calay, E.S.; Tuncman, G.; Claiborn, K.C.; Inouye, K.E.; Eguchi, K.; Alcala, M.; Rathaus, M.; Hollander, K.S.; Ron, I.; et al. The short-chain fatty acid propionate increases glucagon and FABP4 production, impairing insulin action in mice and humans. Sci. Transl. Med. 2019, 11, 13. [CrossRef]

31. Tzounis, X.; Rodriguez-Mateos, A.; Vulevic, J.; Gibson, G.R.; Kwik-Uribe, C.; Spencer, J.P.E. Prebiotic evaluation of cocoa-derived flavanols in healthy humans by using a randomized, controlled, double-blind, crossover intervention study. Am. J. Clin. Nutr. 2011, 93, 62-72. [CrossRef]

32. Espin, J.C.; Gonzalez-Sarrias, A.; Tomas-Barberan, F.A. The gut microbiota: A key factor in the therapeutic effects of (poly) phenols. Biochem. Pharmacol. 2017, 139, 82-93. [CrossRef] [PubMed]

33. Singh, A.K.; Cabral, C.; Kumar, R.; Ganguly, R.; Rana, H.K.; Gupta, A.; Lauro, M.R.; Carbone, C.; Reis, F.; Pandey, A.K. Beneficial effects of dietary polyphenols on gut microbiota and strategies to improve delivery efficiency. Nutrients 2019, 11, 2216. [CrossRef] [PubMed]

34. Alminger, M.; Aura, A.M.; Bohn, T.; Dufour, C.; El, S.N.; Gomes, A.; Karakaya, S.; Martinez-Cuesta, M.C.; McDougall, G.J.; Requena, T; et al. In vitro models for studying secondary plant metabolite digestion and bioaccessibility. Compr. Rev. Food. Sci. Food Saf. 2014, 13, 413-436. [CrossRef]

35. Payne, A.N.; Zihler, A.; Chassard, C.; Lacroix, C. Advances and perspectives in in vitro human gut fermentation modeling. Trends Biotechnol. 2012, 30, 17-25. [CrossRef] [PubMed]

36. Verhoeckx, K.; Cotter, P.; López-Expósito, I.; Kleivelan, C.; Lea, T.; Mackie, A.; Requena, T.; Swiatecka, D.; Wichers, H. The Impact of Food Bioactives on Health: In Vitro and Ex Vivo Models; Springer International Publishing: Berlin/Heidelberg, Germany, 2015.

37. Ekbatan, S.S.; Sleno, L.; Sabally, K.; Khairallah, J.; Azadi, B.; Rodes, L.; Prakash, S.; Donnelly, D.J.; Kubow, S. Biotransformation of polyphenols in a dynamic multistage gastrointestinal model. Food Chem. 2016, 204, 453-462. [CrossRef]

38. Sanchez-Patán, F.; Barroso, E.; van de Wiele, T.; Jiménez-Giron, A.; Martin-Alvarez, P.J.; Moreno-Arribas, M.V.; Martínez-Cuesta, M.C.; Peláez, C.; Requena, T.; Bartolomé, B. Comparative in vitro fermentations of cranberry and grape seed polyphenols with colonic microbiota. Food Chem. 2015, 183, 273-282. [CrossRef] 
39. Cueva, C.; Jiménez-Girón, A.; Muñoz-González, I.; Esteban-Fernández, A.; Gil-Sánchez, I.; Dueñas, M.; Martin-Álvarez, P.J.; Pozo-Bayon, M.A.; Bartolomé, B.; Moreno-Arribas, M.V. Application of a new Dynamic Gastrointestinal Simulator (SIMGI) to study the impact of red wine in colonic metabolism. Food Res. Int. 2015, 72, 149-159. [CrossRef]

40. Colina-Coca, C.; González-Peña, D.; de Ancos, B.; Sanchez-Moreno, C. Dietary onion ameliorates antioxidant defence, inflammatory response, and cardiovascular risk biomarkers in hypercholesterolemic Wistar rats. J. Funct. Food. 2017, 36, 300-309. [CrossRef]

41. González-Peña, D.; Dudzik, D.; García, A.; De Ancos, B.; Barbas, C.; Sánchez-Moreno, C. Metabolomic fingerprinting in the comprehensive study of liver changes associated with onion supplementation in hypercholesterolemic Wistar rats. Int. J. Mol. Sci. 2017, 2, 267. [CrossRef]

42. Benitez, V.; Molla, E.; Martín-Cabrejas, M.A.; Aguilera, Y.; López-Andreu, F.J.; Esteban, R.M. Onion (Allium cepa L.) by-products as source of dietary fiber: Physicochemical properties and effect on serum lipid levels in high-fat fed rats. Eur. Food Res. Technol. 2012, 234, 617-625. [CrossRef]

43. Galdón, B.R.; Rodríguez, C.T.; Rodríguez, E.R.; Romero, C.D. Organic acid contents in onion cultivars (Allium cepa L.). J. Agric. Food Chem. 2008, 56, 6512-6519. [CrossRef]

44. Liguori, L.; Califano, R.; Albanese, D.; Raimo, F.; Crescitelli, A.; Di Matteo, M. Chemical composition and antioxidant properties of five white onion (Allium cepa L.) landraces. J. Food Qual. 2017, 2017, 6873651. [CrossRef]

45. Fernández-Jalao, I.; Sanchez-Moreno, C.; De Ancos, B. Effect of high-pressure processing on flavonoids, hydroxycinnamic acids, dihydrochalcones and antioxidant activity of apple 'Golden Delicious' from different geographical origin. Innov. Food Sci. Emerg. Technol. 2019, 51, 20-31. [CrossRef]

46. Fernández-Jalao, I.; Sanchez-Moreno, C.; De Ancos, B. Influence of food matrix and high-pressure processing on onion flavonols and antioxidant activity during gastrointestinal digestion. J. Food Eng. 2017, 213, 60-68. [CrossRef]

47. Gorinstein, S.; Leontowicz, H.; Leontowicz, M.; Namiesnik, J.; Najman, K.; Drzewieck, J.; Cvikrova, M.; Martincova, O.; Katrich, E.; Trakhtenberg, S. Comparison of the main bioactive compounds and antioxidant activities in garlic and white and red onions after treatment protocols. J. Agric. Food Chem. 2008, 56, 4418-4426. [CrossRef]

48. Cardona, F.; Andres-Lacueva, C.; Tulipani, S.; Tinahones, F.J.; Queipo-Ortuno, M.I. Benefits of polyphenols on gut microbiota and implications in human health. J. Nutr. Biochem. 2013, 24, 1415-1422. [CrossRef]

49. Juániz, I.; Ludwig, I.A.; Bresciani, L.; Dall'Asta, M.; Mena, P.; Del Rio, D.; Cid, C.; de Peña, M.P. Catabolism of raw and cooked green pepper (Capsicum annuum) (poly)phenolic compounds after simulated gastrointestinal digestion and faecal fermentation. $J$. Funct. Food. 2016, 27, 201-213. [CrossRef]

50. Rechner, A.R.; Smith, M.A.; Kuhnle, G.; Gibson, G.R.; Debnam, E.S.; Srai, S.K.S.; Moore, K.P.; Rice-Evans, C.A. Colonic metabolism of dietary polyphenols: Influence of structure on microbial fermentation products. Free Radic. Biol. Med. 2004, 36, 212-225. [CrossRef] [PubMed]

51. Rowland, I.; Gibson, G.; Heinken, A.; Scott, K.; Swann, J.; Thiele, I.; Tuohy, K. Gut microbiota functions: Metabolism of nutrients and other food components. Eur. J. Nutr. 2018, 57, 1-24. [CrossRef] [PubMed]

52. Tomas-Barberán, F.A.; Espín, J.C. Effect of food structure and processing on (poly)phenol-gut microbiota interactions and the effects on human health. In Annual Review of Food Science and Technology; Doyle, M.P., McClements, D.J., Eds.; Annual Reviews: Palo Alto, CA, USA, 2019; Volume 10, pp. 221-238.

53. Gil-Sánchez, I.; Cueva, C.; Sanz-Buenhombre, M.; Guadarrama, A.; Moreno-Arribas, M.V.; Bartolomé, B. Dynamic gastrointestinal digestion of grape pomace extracts: Bioaccessible phenolic metabolites and impact on human gut microbiota. J. Food Compos. Anal. 2018, 68, 41-52. [CrossRef]

54. Serra, A.; Macia, A.; Romero, M.P.; Angles, N.; Morello, J.R.; Motilva, M.J. Metabolic pathways of the colonic metabolism of procyanidins (monomers and dimers) and alkaloids. Food Chem. 2011, 126, 1127-1137. [CrossRef]

55. Boto-Ordóñez, M.; Urpi-Sarda, M.; Queipo-Ortuño, M.I.; Tulipani, S.; Tinahones, F.J.; Andres-Lacueva, C. High levels of Bifidobacteria are associated with increased levels of anthocyanin microbial metabolites: A randomized clinical trial. Food Funct. 2014, 5, 1932-1938. [CrossRef] [PubMed]

56. Stalmach, A.; Edwards, C.A.; Wightman, J.D.; Crozier, A. Colonic catabolism of dietary phenolic and polyphenolic compounds from Concord grape juice. Food Funct. 2013, 4, 52-62. [CrossRef] [PubMed]

57. Williamson, G.; Kay, C.D.; Crozier, A. The bioavailability, transport, and bioactivity of dietary flavonoids: A Review from a historical perspective. Compr. Rev. Food. Sci. Food Saf. 2018, 17, 1054-1112. [CrossRef]

58. Mosele, J.I.; Macia, A.; Romero, M.P.; Motilva, M.J. Stability and metabolism of Arbutus unedo bioactive compounds (phenolics and antioxidants) under in vitro digestion and colonic fermentation. Food Chem. 2016, 201, 120-130. [CrossRef]

59. Gao, K.; Xu, A.L.; Krul, C.; Venema, K.; Liu, Y.; Niu, Y.T.; Lu, J.X.; Bensoussan, L.; Seeram, N.P.; Heber, D.; et al. Of the major phenolic acids formed during human microbial fermentation of tea, citrus, and soy flavonoid supplements, only 3,4dihydroxyphenylacetic acid has antiproliferative activity. J. Nutr. 2006, 136, 52-57. [CrossRef]

60. Xue, H.T.; Xie, W.Y.; Jiang, Z.H.; Wang, M.; Wang, J.; Zhao, H.Q.; Zhang, X.Y. 3,4-Dihydroxyphenylacetic acid, a microbiotaderived metabolite of quercetin, attenuates acetaminophen (APAP)-induced liver injury through activation of Nrf-2. Xenobiotica 2016, 46, 931-939. [CrossRef] 
61. Monagas, M.; Khan, N.; Andres-Lacueva, C.; Urpi-Sarda, M.; Vázquez-Agell, M.; Lamuela-Raventos, R.M.; Estruch, R. Dihydroxylated phenolic acids derived from microbial metabolism reduce lipopolysaccharide-stimulated cytokine secretion by human peripheral blood mononuclear cells. Br. J. Nutr. 2009, 102, 201-206. [CrossRef]

62. Tang, Y.; Nakashima, S.; Saiki, S.; Myoi, Y.; Abe, N.; Kuwazuru, S.; Zhu, B.W.; Ashida, H.; Murata, Y.; Nakamura, Y. 3,4Dihydroxyphenylacetic acid is a predominant biologically-active catabolite of quercetin glycosides. Food Res. Int. 2016, 89, 716-723. [CrossRef] [PubMed]

63. Najmanova, I.; Pourova, J.; Voprsalova, M.; Pilarova, V.; Semecky, V.; Novakova, L.; Mladenka, P. Flavonoid metabolite 3-(3hydroxyphenyl)propionic acid formed by human microflora decreases arterial blood pressure in rats. Mol. Nutr. Food Res. 2016, 60, 981-991. [CrossRef] [PubMed]

64. Barroso, E.; Cueva, C.; Peláez, C.; Martínez-Cuesta, M.C.; Requena, T. Development of human colonic microbiota in the computer-controlled dynamic SIMulator of the GastroIntestinal tract SIMGI. LWT-Food Sci. Technol. 2015, 61, 283-289. [CrossRef]

65. Valdés, L.; Cuervo, A.; Salazar, N.; Ruas-Madiedo, P.; Gueimonde, M.; González, S. The relationship between phenolic compounds from diet and microbiota: Impact on human health. Food Funct. 2015, 6, 2424-2439. [CrossRef]

66. Duque, A.; Monteiro, M.; Adorno, M.A.T.; Sakamoto, I.K.; Sivieri, K. An exploratory study on the influence of orange juice on gut microbiota using a dynamic colonic model. Food Res. Int. 2016, 84, 160-169. [CrossRef]

67. Sanchez-Patán, F.; Cueva, C.; Monagas, M.; Walton, G.E.; Gibson, G.R.; Martín-Álvarez, P.J.; Moreno-Arribas, M.V.; Bartolomé, B. Gut microbial catabolism of grape seed flavan-3-ols by human faecal microbiota. Targeted analysis of precursor compounds, intermediate metabolites and end-products. Food Chem. 2012, 131, 337-347. [CrossRef]

68. Pascoal, G.B.; Filisetti, T.M.C.C.; Alvares, E.P.; Lajolo, F.M.; Menezes, E.W. Impact of onion (Allium cepa L) fructans fermentation on the cecum of rats and the use of in vitro biomarkers to assess in vivo effects. Bioact. Carbohydr. Diet. Fibre 2013, 1, 89-97. [CrossRef]

69. Jakobsdottir, G.; Blanco, N.; Xu, J.; Ahrné, S.; Molin, G.; Sterner, O.; Nyman, M. Formation of short-chain fatty acids, excretion of anthocyanins, and microbial diversity in rats fed blackcurrants, blackberries, and raspberries. Int. J. Nutr. Metab. 2013, 2013, 202534. [CrossRef]

70. González-Peña, D.; Colina-Coca, C.; Char, C.D.; Cano, M.P.; de Ancos, B.; Sanchez-Moreno, C. Hyaluronidase inhibiting activity and radical scavenging potential of flavonols in processed onion. J. Agric. Food Chem. 2013, 61, 4862-4872. [CrossRef]

71. Colina-Coca, C.; De Ancos, B.; Sánchez-Moreno, C. Nutritional composition of processed onion: S-alk(en)yl-L-cysteine sulfoxides, organic acids, sugars, minerals, and vitamin C. Food Bioprocess. Technol. 2014, 7, 289-298. [CrossRef]

72. Bradford, M.M. Rapid and sensitive method for quantitation of microgram quantities of protein utilizing principle of protein-dye binding. Anal. Biochem. 1976, 72, 248-254. [CrossRef]

73. Van de Wiele, T.R.; Oomen, A.G.; Wragg, J.; Cave, M.; Minekus, M.; Hack, A.; Cornelis, C.; Rompelberg, C.J.M.; De Zwart, L.L.; Klinck, B.; et al. Comparison of five in vitro digestion models to in vivo experimental results: Lead bioaccessibility in the human gastrointestinal tract. J. Environ. Sci. Health Part. A-Toxic/Hazard. Subst. Environ. Eng. 2007, 42, 1203-1211. [CrossRef]

74. Marzorati, M.; Verhelst, A.; Luta, G.; Sinnott, R.; Verstraete, W.; Van de Wiele, T.; Possemiers, S. In vitro modulation of the human gastrointestinal microbial community by plant-derived polysaccharide-rich dietary supplements. Int. J. Food Microbiol. 2010, 139, 168-176. [CrossRef]

75. Minekus, M.; Alminger, M.; Alvito, P.; Ballance, S.; Bohn, T.; Bourlieu, C.; Carrière, F.; Boutrou, R.; Corredig, M.; Dupont, D.; et al. A standardized static in vitro digestion method suitable for food. An international consensus. Food Funct. 2014, 5, 1113-1124. [CrossRef]

76. Molly, K.; Vandewoestyne, M.; Desmet, I.; Verstraete, W. Validation of the simulator of the human intestinal microbial ecosystem (shime) reactor using microorganism-associated activities. Microb. Ecol. Health Dis. 1994, 7, 191-200. [CrossRef]

77. Molly, K.; Woestyne, M.V.; Verstraete, W. Development of a 5-step multichamber reactor as a simulation of the human intestinal microbial ecosystem. Appl. Microbiol. Biotechnol. 1993, 39, 254-258. [CrossRef] [PubMed]

78. Kontula, P.; Jaskari, J.; Nollet, L.; De Smet, I.; von Wright, A.; Poutanen, K.; Mattila-Sandholm, T. The colonization of a simulator of the human intestinal microbial ecosystem by a probiotic strain fed on a fermented oat bran product: Effects on the gastrointestinal microbiota. Appl. Microbiol. Biotechnol. 1998, 50, 246-252. [CrossRef]

79. Tannock, G.W.; Munro, K.; Harmsen, H.J.M.; Welling, G.W.; Smart, J.; Gopal, P.K. Analysis of the fecal microflora of human subjects consuming a probiotic product containing Lactobacillus rhamnosus DR20. Appl. Environ. Microbiol. 2000, 66, 2578-2588. [CrossRef] [PubMed]

80. Bunesova, V.; Killer, J.; Vlkova, E.; Musilova, S.; Tomaska, M.; Rada, V.; Kmet, V. Isolation and characterization of bifidobacteria from ovine cheese. Int. J. Food Microbiol. 2014, 188, 26-30. [CrossRef] [PubMed]

81. Castro-Gómez, F.; Fontecha, J.; Rodriguez-Alcalá, L.M. A high-performance direct transmethylation method for total fatty acids assessment in biological and foodstuff samples. Talanta 2014, 128, 518-523. [CrossRef] [PubMed]

82. Pang, Z.; Chong, J.; Li, S.; Xia, J. MetaboAnalystR 3.0: Toward an Optimized Workflow for Global Metabolomics. Metabolites 2020, 10, 186. [CrossRef] [PubMed] 